\title{
WestVirginiaUniversity
}

THE RESEARCH REPOSITORY @ WVU

Graduate Theses, Dissertations, and Problem Reports

2005

\section{The effectiveness of valdecoxib on post-endodontic pain}

\author{
Lora Beth Ford \\ West Virginia University
}

Follow this and additional works at: https://researchrepository.wvu.edu/etd

\section{Recommended Citation}

Ford, Lora Beth, "The effectiveness of valdecoxib on post-endodontic pain" (2005). Graduate Theses, Dissertations, and Problem Reports. 2286.

https://researchrepository.wvu.edu/etd/2286

This Thesis is protected by copyright and/or related rights. It has been brought to you by the The Research Repository @ WVU with permission from the rights-holder(s). You are free to use this Thesis in any way that is permitted by the copyright and related rights legislation that applies to your use. For other uses you must obtain permission from the rights-holder(s) directly, unless additional rights are indicated by a Creative Commons license in the record and/ or on the work itself. This Thesis has been accepted for inclusion in WVU Graduate Theses, Dissertations, and Problem Reports collection by an authorized administrator of The Research Repository @ WVU. For more information, please contact researchrepository@mail.wvu.edu. 


\title{
THE EFFECTIVENESS OF VALDECOXIB ON POST- ENDODONTIC PAIN
}

\author{
By \\ Lora Beth Ford, D.D.S. \\ Thesis submitted to the \\ School of Dentistry \\ At West Virginia University \\ In partial fulfillment of the requirements \\ For the degree of \\ Master of Science
In
Endodontics \\ C. Russell Jackson D.D.S., M.S. Chair \\ Michael Bagby D.D.S., M.S., Ph.D. \\ Charles D. Ponte Pharm. D., C.D.E., B.C.P.S.
}

Department of Endodontics

Morgantown, West Virginia 2005 


\section{ABSTRACT \\ The Effectiveness of Valdecoxib on Post-Endodontic Pain}

\section{Lora Beth Ford, DDS}

Pain is often associated with teeth that need endodontic therapy. This pain results from inflammation. Non-Steroidal Anti-Inflammatory Drugs are useful in managing acute post-operative dental pain. NSAIDS specific for only blocking the COX-2 enzyme cause less stomach irritation and bleeding. The purpose of this clinical study was to determine if pre-operative administration of valdecoxib would significantly reduce postendodontic pain, when compared to ibuprofen. Sixteen patients were evaluated. The patients consented to a random, one-time, pre-operative oral administration of either 600 $\mathrm{mg}$ ibuprofen or $20 \mathrm{mg}$ valdecoxib. Each patient rated their pain on a visual analog scale at initial, immediately after, 4, 8, 12, 24, 48, and 72 hours after initiation of endodontic therapy. Statistical analysis with a two factor ANOVA showed there was no significant difference ( $\mathrm{p}>0.05)$ between valdecoxib and ibuprofen at controlling post-endodontic pain over time. In conclusion, valdecoxib and ibuprofen appear to have equal efficacy at controlling post-endodontic pain when administered pre-operatively. 


\section{DEDICATION}

To my Mom, Ginger Mckay, for her unconditional love and support throughout my education. Without her saying, "the present pays for the future”, I would not be here. She's my guardian angel and I know she still watches over me from above. I love you Mom.

To my husband, Eric Ford, for believing in me, supporting me and loving me.

To my son, Jacob, who is my sweetest blessing. I'm so lucky to be your Mommy. 


\section{ACKNOWLEDGEMENTS}

I would like to thank Dr. Russ Jackson for giving me the opportunity to become an endodontist and for his insight and guidance during my education.

To Dr. Mike Bagby, thank you for your assistance with the statistical and graphic help for this thesis. I could not have done it without you.

To Dr. Charles Ponte, thank you for serving on my committee and for your expertise into the pharmacology aspect of this thesis.

To Dr. Pam Harrington, I want to thank you for being a wonderful co-resident and friend these past two years. Thank you for your support, recipes, coffee, advice, and friendship. I can't imagine having gone through this with anyone but you. I will miss you. Stay warm in Duluth, snow-walker.

I would like to thank Dr. Jeff Minchau for his friendship and guidance. You and Beth have become such good friends of ours. Your hand in my education was invaluable and I appreciate it so much. You really are a kind and generous person.

To Dr. Wayne Hughart, for your advice, sense of humor, and guidance during my first year.

Dr. Lori Gochenour, for your help and sweet disposition. You are a talented endodontist.

To Drs.Rodney Southern and Jamie Day, thank you for making this year so much fun and for being such hard working residents!

To Marilyn Powley, thank you for being such a fun person to be around. You always made me smile. Thanks for the computer help but most of all for your cute laugh and good sense of humor.

To Gina White, thanks for being a great assistant and for always being cheerful!

To Cathy Myers, thank you for your assistance these past two years. I'll be calling you for some "green thumb" advice when I finally have a yard!

Also thank you Dr. Morgan for being so sweet and helpful in our student clinic. We appreciate the time this gave us.

Last but not least, to Yetta Bretzman, How do I thank you enough? Your computer expertise has saved me! I really appreciate the time you spent to help me. 


\section{TABLE OF CONTENTS}

THE EFFECTIVENESS OF VALDECOXIB ON POST-ENDODONTIC PAIN .................. i

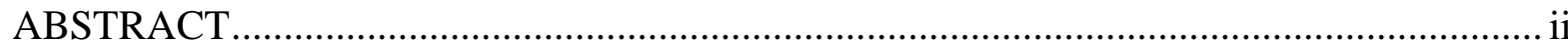

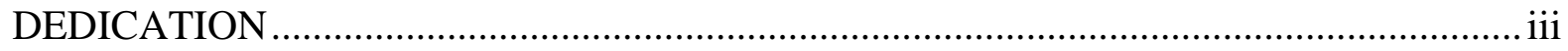

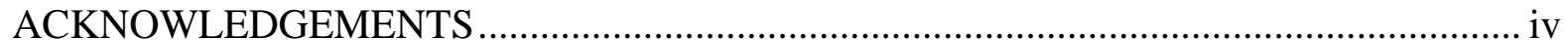

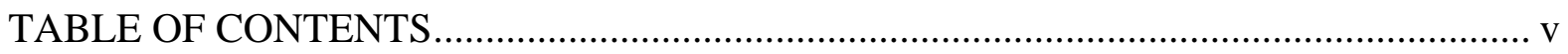

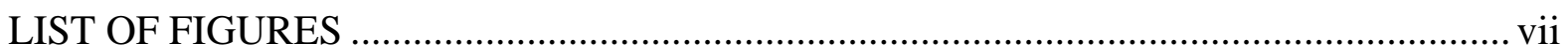

LIST OF TABLES .................................................................................................... vii

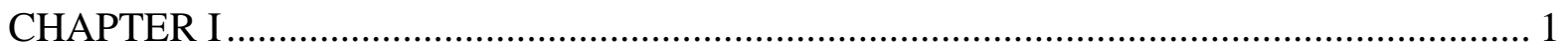

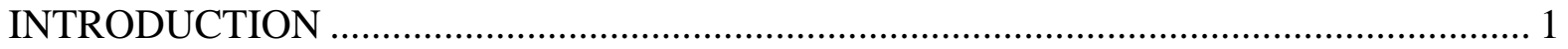

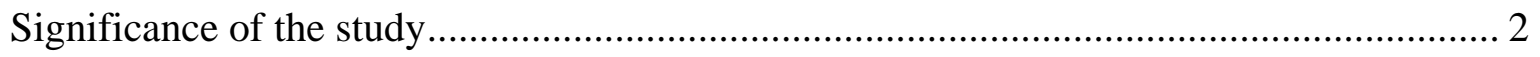

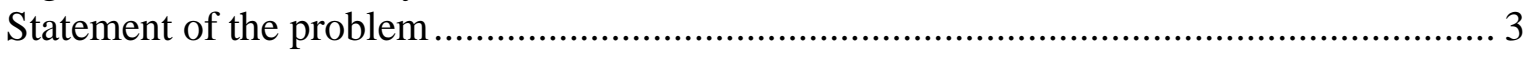

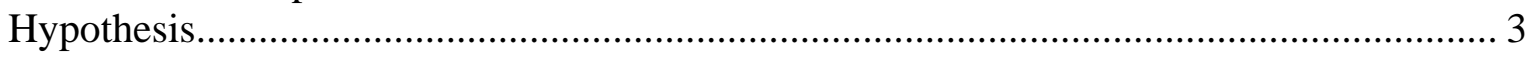

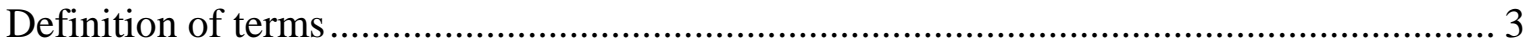

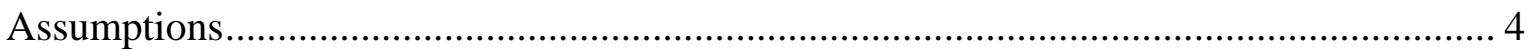

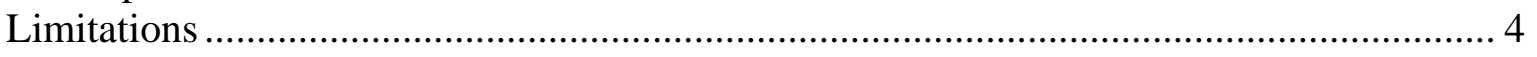

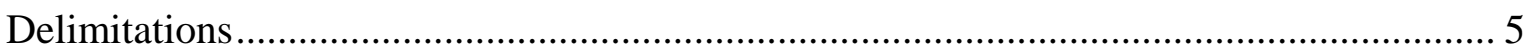

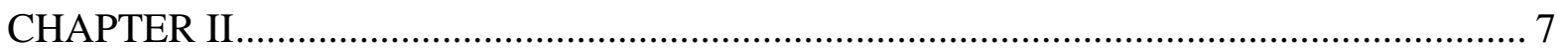

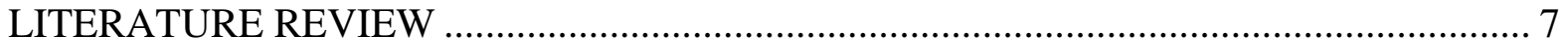

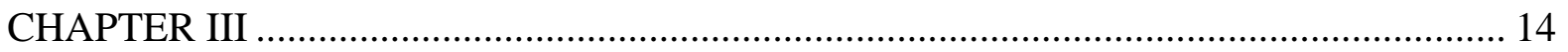

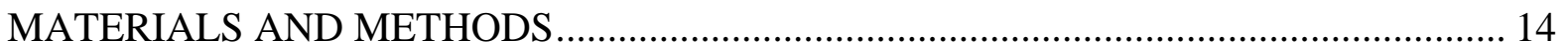

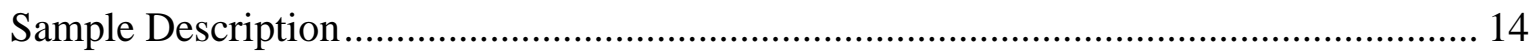

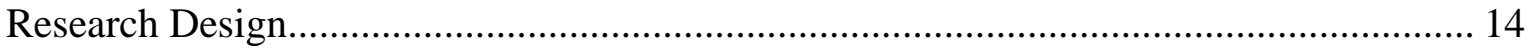

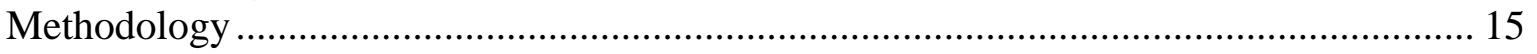

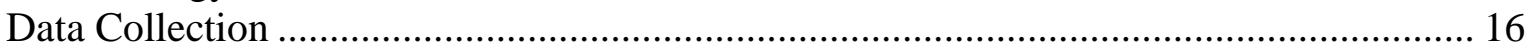

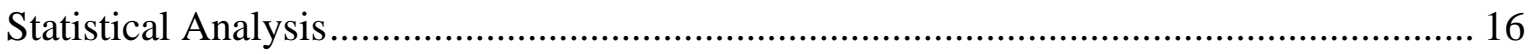

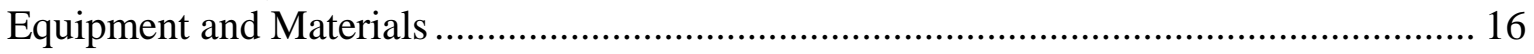

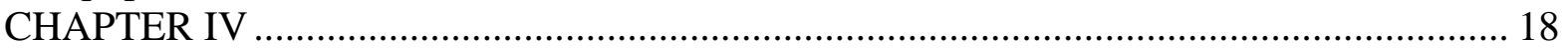

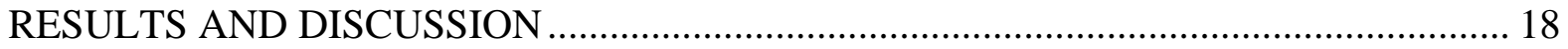

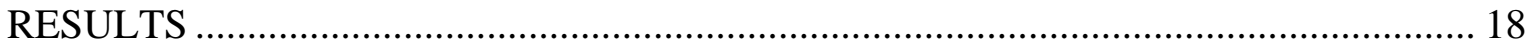

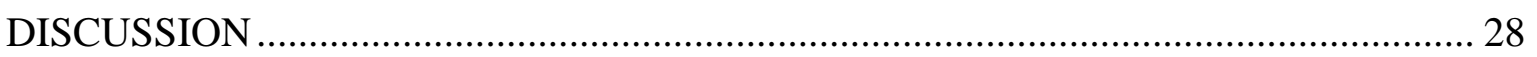

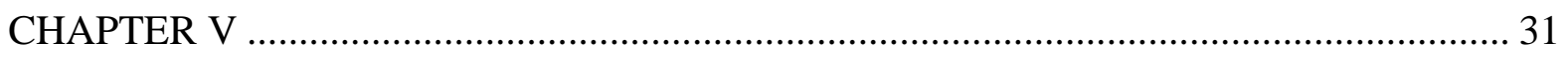

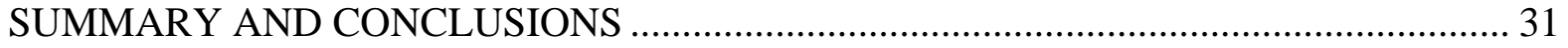

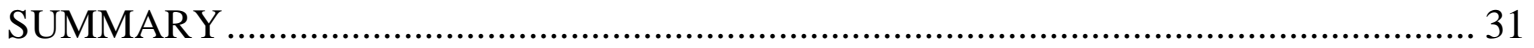

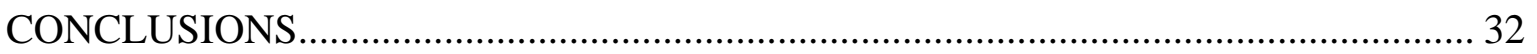

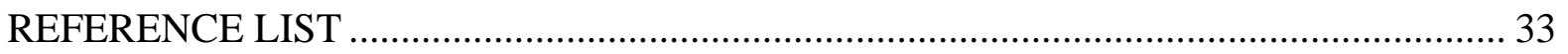

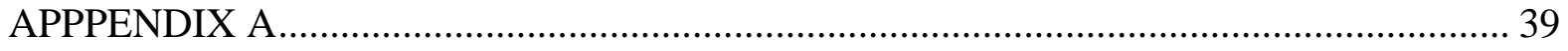

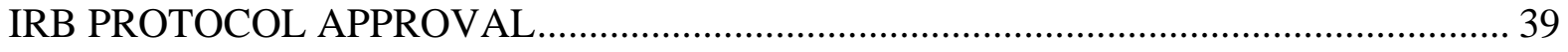

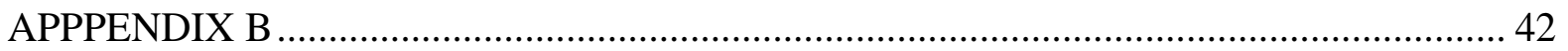




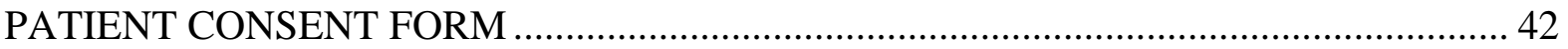

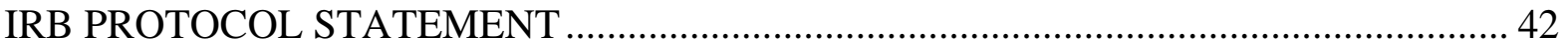

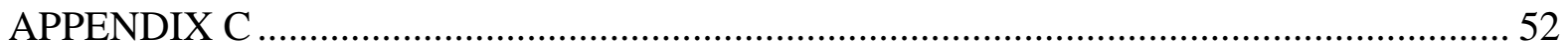

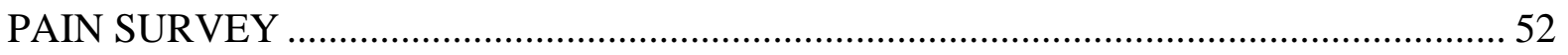

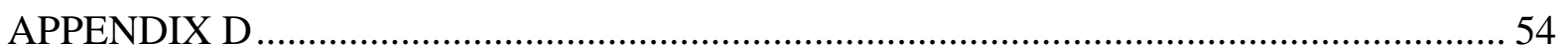

PULPAL AND PERIAPICAL DIAGNOSIS FLOW CHARTS ....................................... 54

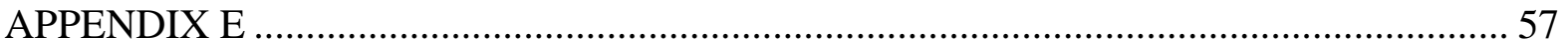

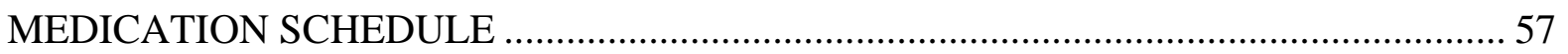

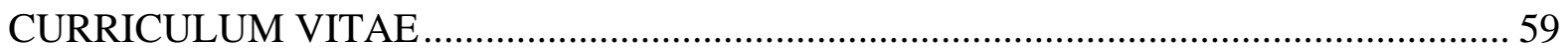




\section{LIST OF FIGURES}

Figure 1. Experimental Medication and Pain Relief Over Time ...................................... 22

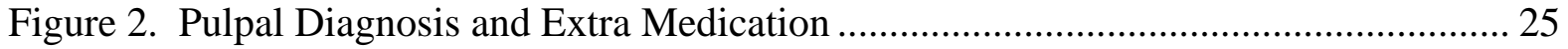

Figure 3. Periapical Diagnosis and Extra Medication .................................................... 27 


\section{LIST OF TABLES}

Table 1. Data Collection Sheet ................................................................................. 20

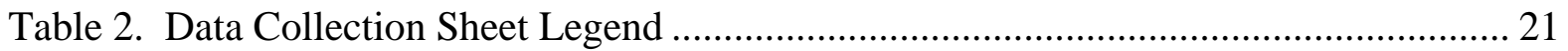

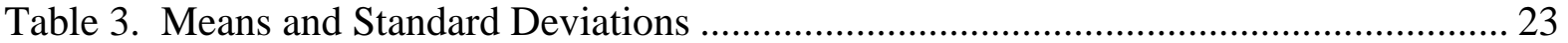

Table 4. Pulpal Diagnosis and Additional Medication ................................................... 24

Table 5. Periapical Diagnosis and Additional Medication ................................................ 26 


\section{CHAPTER I}

\section{INTRODUCTION}

Endodontic therapy can be a pain free experience but there are occasions when some discomfort can be expected. Patients often seek treatment because they are already in pain of odontogenic origin. Root canal therapy is initiated in order to reduce this pain. When pain is severe before endodontic therapy, pain can also be expected to be of a moderate to severe intensity after therapy.(1)

The pain that is experienced is due to pulpal and or periapical insult which results in inflammation. The inflammatory process that occurs after tissue injury is mediated by the breakdown of damaged cell membranes by phospholipase A2 into their fatty acid components. The main fatty acid component is arachidonic acid which is then converted to prostaglandins, prostacyclins, and thromboxanes by various cyclooxygenase (COX) enzymes. Prostaglandins are involved in hyperalgesia and inflammation. They sensitize nerve endings and initiate vasodilation seen in edema.(2)

There are two forms of the cyclooxygenase enzyme that result in the formation of inflammatory products from the arachidonic acid cascade. The first isoform is COX-1 and is responsible for normal homeostatic functions of prostaglandins. Prostaglandins found in the gastrointestinal tract help maintain gastric mucosal integrity. They are also found in blood

platelets and help initiate aggregation. Prostaglandins associated with COX-1 are normally found in the kidneys where they help regulate renal blood flow.(3) COX-2 is primarily an inducible enzyme that is not found in most tissues under normal conditions but is produced in response to pain and inflammation.(4) It is also expressed in the brain and the kidneys but its role there is still undefined.(5)

Management of pain and inflammation has been accomplished with different medications over the years. Traditional Non-Steroidal Anti-Inflammatory Drugs (NSAIDS) are a major drug class that have been useful in these situations and have been used in 
managing acute post-operative dental pain. However, many NSAIDS have undesirable side effects like GI irritation/toxicity, ulcers and bleeding. These side effects could be avoided by using selective COX-2 inhibitors. This newer drug class of COX-2 inhibitors has been shown to produce therapeutic efficacy comparable to current NSAIDS but without the GI and renal toxicity that contributes directly to the morbidity associated with chronic NSAID administration.(6)

Valdecoxib is a selective COX-2 inhibitor. Studies show it has as effective or superior analgesic effects to traditional NSAIDS but without the associated side effects of nonselective NSAIDS.(7) Also, valdexcoxib has shown a quicker onset of analgesia, significantly improved pain relief, and lower pain intensity when taken for post-oral surgery pain.(8) If valdecoxib has comparable analgesic effects to ibuprofen for the management of acute pain, but without the adverse side effects, then it might be an important medication used in the treatment of acute pain of odontogenic origin. The ability of valdecoxib to control post-endodontic pain when administered pre-operatively has not been evaluated. The goal of this study is to determine if valdecoxib will significantly reduce post-endodontic pain when compared to ibuprofen.

\section{Significance of the study}

Pain can be associated with root canal therapy before and after treatment. This is due to the inflammatory process and its components. The standard post-op medication for pain associated with inflammation is ibuprofen, a common NSAID. It inhibits both COX-1 and COX-2 enzymes. Valdecoxib is also an NSAID that exhibits anti-inflammatory, analgesic, and antipyretic properties with less gastric side effects. It does this by selectively inhibiting only the COX-2 enzyme. If valdexcoxib is more effective than ibuprofen in reducing postendodontic pain, with less gastric side effects, then it could be used for patients needing root canal therapy. 


\section{Statement of the problem}

Is there a difference between ibuprofen and valdecoxib in controlling post endodontic treatment pain when administered preoperatively?

\section{Hypothesis}

There is no difference between ibuprofen and valdecoxib in controlling postendodontic treatment pain.

\section{Definition of terms}

- Endodontic Pain: Pain that a patient experiences due to inflammation and/or necrosis of the tooth pulp and periapical tissues.

- Cyclooxygenase-1 (COX-1) enzyme: This enzyme catalyzes the conversion of arachidonic acid to prostaglandin $\mathrm{H} 2$, the precursor of prostaglandins and thromboxane. It is thought that this enzyme is found normally in the stomach, kidneys and platelets. It produces prostaglandins that are beneficial to renal and gastric function.

- Cyclooxygenase-2 (COX-2) enzyme: This enzyme also catalyzes the conversion of arachidonic to prostaglandin $\mathrm{H} 2$. This enzyme is normally present in the tissues in low levels and is associated with the mediation of inflammation and pain. It is also expressed in the brain and kidneys.

- Valdecoxib: An oral, nonsteroidal anti-inflammatory drug which selectively inhibits prostaglandin synthesis by decreasing the activity of the COX-2 enzyme, resulting in analgesic, antipyretic, and anti-inflammatory pharmacological effects.

- Ibuprofen: An NSAID which inhibits both COX-1 and COX-2 when controlling pain associated with inflammation.

- Visual Analog Scale: A 100 millimeter horizontal scale used to measure a person's perception of pain. Zero is on the extreme left and equals "no pain", while one hundred is on the extreme right and equals "pain so severe you can’t stand it."

- Pulpal and Periapical Diagnoses: These are determined for each patient by collecting clinical data through appropriate diagnostic tests. 
- Acute Apical Periodontitis: An endodontic diagnosis involving inflammation of the apical periodontium which produces acute symptoms of pain upon biting, percussion and palpation. This is usually a result of an inflamed or dying pulp.

- Phoenix Abscess: A condition where the patient exhibits pain upon biting or occlusal contact, radiographically a radiolucency is located around the apex or apices of the root of the tooth, but there is no swelling or sinus tract.

- Acute Apical Abscess: An inflammatory reaction to pulpal infection and necrosis characterized by rapid onset, spontaneous pain, tenderness of the tooth to pressure, pus formation and swelling of associated tissues.

- Chronic Apical Periodontitis: Inflammation and destruction of the apical periodontium that is of pulpal origin. Radiographically it appears as a radiolucent area around the roots of the tooth and does not produce any clinical symptoms.

- Necrotic Pulp: A clinical diagnosis based on subjective and objective findings that indicate that the pulp has undergone necrosis and death.

- Irreversible Pulpitis: Inflammation of the pulp that is severe enough that the pulp will not be able to recover and will eventually die.

- Reversible Pulpitis: Inflammation that is not severe enough to cause pulpal death and the pulp can recover if the cause of the irritation is eliminated.

- Chronic Apical Abscess: A chronic condition where there is no pain but an abscess or sinus tract associated with a lesion around the apices of a tooth.

\section{Assumptions}

Pain due to inflammation is associated with endodontic therapy. Standard nonspecific NSAIDS block both COX-1 and COX-2 enzymes which can produce unwanted side effects. Patients who exhibit pain pre-operatively are likely to exhibit pain post-operatively.

\section{Limitations}

- $\quad$ Pre-operative and post-operative pain may differ in each patient

- Valdecoxib and ibuprofen may affect patients differently

- $\quad$ The patient must return the pain survey 
- Endodontic diagnosis is not exact all the time

- The age of the patient may cause differences in pain perception

- There are gender and cultural differences among patients

- Different teeth among patients will be treated

- Health histories differ between patients

\section{Delimitations}

- A pulpal diagnosis of irreversible pulpitis or necrotic pulp and pain is necessary

- A periapical diagnosis of acute apical periodontitis or phoenix abscess is necessary

- Patients must be at least 18 years of age

- Patients must not be taking antibiotics

- Patients with the following conditions will not be included in the study:

- Mitral Valve Prolapse

- Rheumatic Heart Disease

- Artificial joints or heart valves

- Stroke

- Untreated hypertension or hyperthyroidism

- Myocardial Infarction

- Hepatitis

- Bleeding Disorders

- Stomach ulcers

- Epilepsy

- Kidney problems 
- Liver problems

- Pregnant females or intending to become pregnant

- Allergy or contraindication to the use of NSAIDS

- Patient history of rashes

- Allergy to Sulfa drugs

- Alcoholism

- Systemic Lupus Erythematosus

- Patients taking coumadin or other anticoagulants

- Patients allergic to codeine 


\section{CHAPTER II}

\section{LITERATURE REVIEW}

Patients requiring endodontic therapy often have pain secondary to inflammation and therefore seek treatment. Pain is not always associated with teeth in need of root canal therapy. Unfortunately, it is the cases where pain is present that the public has a negative association with having root canal treatment. When patients present in pain before root canal therapy, they will often have pain after treatment.(1) Root canal therapy is initiated to remove the source of the problem and to help alleviate this discomfort. Due to factors associated with inflammation and the procedure itself, total resolution of pain might not be possible.

There are different diagnoses in endodontics that can be associated with pain. Patients who exhibit signs of acute apical periodontitis or phoenix abscess are experiencing pain. In these cases, the tooth is painful to percussion or palpation. This discomfort is secondary to inflammation of the surrounding periodontal tissues of the tooth involved.

Even though endodontic therapy is initiated to help relieve pain, the procedure itself can cause some post-operative discomfort. In a study done by Seltzer and Bender, they found that $40 \%$ of 698 patients experienced slight discomfort after root canal therapy. They also found that patients with acute periodontitis had a higher incidence of pain that when compared to chronic periodontitis. The stage of instrumentation was not related to incidence or duration of pain.(9) Treatment procedures or iatrogenic factors during root canal therapy can lead to some post-operative discomfort. Irrigation with 3\% hydrogen peroxide and 5.25\% sodium hypochlorite, and intracanal medication between appointments with formocresol have a lower incidence of and degree of post-obturation pain when compared to teeth that are irrigated with saline and when no intracanal medication is placed between appointments.(10) Teeth that have been over-instrumented beyond the apex, and sealer or gutta percha has been extruded out the apical area, can result in a higher incidence and 
degree of post-obturation pain. They also noted that post-obturation pain occurred with the highest incidence during the first 24 hours after treatment.(11)

Researchers have studied single visit endodontic treatment versus multi-visit treatment regarding post-operative pain. Soltanoff compared the effects of single visit endodontic treatment or multiple visit treatment based on random selection of cases performed in clinical practice during a period of twenty years. He found out of 135 single visit cases and 195 multiple visit cases, significantly more patients in the multi-visit group had no pain than in the single visit group.(12) Other studies have shown the opposite effect though. Roane et al. found that out of 359 cases a 2 to 1 higher frequency of pain was reported following multi-visit treatment compared to single visit treatment.(13) Okeefe found no significant difference in post-operative pain and the number of visits.(1) Factors such as pre-operative pain, treatment methods, anatomic type of tooth, and pulpal/periapical diagnosis could be reasons for variations in these conflicting research findings.

Sometimes it is not the number of visits, but the clinical diagnosis that best predicts pain after treatment or "flare-ups". Trope compared the flare-up rate for single visit root canal therapy among teeth with and without clinical and radiographic signs of apical periodontitis not previously treated and those with apical periodontitis requiring retreatment. He found teeth without apical periodontitis, did not flare up and could be treated in one appointment. Teeth with apical periodontitis had a low flare-up rate. Teeth with apical periodontitis needing retreatment had the highest flare-up rates. He also found that thorough instrumentation of canals was the most important factor in decreasing the incidence of pain.(14)

Along with periapical factors as predictors of flare-ups, microorganisms should also be considered. Siqueira found that certain situations during endodontic treatment facilitate the disruption of balance between host defenses and microbial aggression.(15) These include apical extrusion of infected debris, incomplete chemo-mechanical preparation of the canals, and secondary infection of the canal. Preventive measures are suggested to help minimize these things from occurring. Selection of instrumentation techniques that extrude less amounts of debris apically, use of an antimicrobial intracanal medication between appointments, and not leaving the tooth open to the oral environment are a few.(16) Balaban 
et al. found that thorough cleansing of the canal system during the first treatment appointment produced no additional exacerbations and decreased treatment time.(17)

Pain that is associated with endodontic therapy can be attributed to the inflammatory response. When a tooth requires root canal therapy there has been some form of insult or injury to the pulpal tissue. This insult could be traumatic, chemical, mechanical, or bacterial. Whatever the cause the insult may have been, the inner network of nerves and blood vessels has been irreversibly affected. A series of events takes place when this type of insult or injury occurs. First, there is an increased vascular response which leads to vasodilation and increased vascular permeablility. There is also release of chemical mediators such as histamine, serotonin, kinins, and metabolites of arachidonic acid which are prostaglandins, endoperoxides and prostacycline.(2) Prostaglandins have been associated with pain. They are involved in normal and pathologic processes and play important roles in inflammation. They are formed in response to various stimuli. Their precursor, arachidonic acid is formed from the action of phospholipase A2 on membrane phospholipids. From this point arachidonic acid is metabolized by two different pathways, the cyclooxygenase or lipoxygenase pathway. It is from the cyclooxygenase pathway that prostaglandins are derived. Prostaglandins increase vascular permeablility, induce fever, raise chemotactic activity and increase the sensitivity of pain receptors to other inflammatory mediators.(2) There are two forms of the cyclooxygenase enzyme. One form is COX-1, which is responsible for normal homeostatic functions of prostaglandins in the gastrointestinal tract that help to maintain mucosal integrity, initiate platelet aggregation, and regulate renal blood flow. COX-2 is believed to be induced during inflammation and contributes to pain, edema and tissue destruction. COX-2 is found in the brain and kidneys but plays an undefined role in these tissues.(18) According to Torabinejad and Bakland, histamine, bradykinin, and prostaglandins are the most important chemical mediators of acute inflammation.(19) Cooper states that as these mediators build up in injured tissues, more pain impulses reach the central nervous system. In the spinal column, a transmitter known as substance $\mathrm{P}$ is released and this activates the spinal pain pathways leading to the brain.(20) Once the brain receives these impulses, it releases transmitters called endorphins and enkephalins to help relieve pain. 
There are also exogenous ways to help alleviate this pain. Cooper states that there are two major drug classes to treat pain. The first group is peripherally acting analgesics that work at the site of injury. The second group is centrally acting analgesics that work in the brain.(21) The peripherally acting analgesics block the cyclooxygenase that converts arachidonic acid to prostaglandins. These drugs are referred to as Non-Steroidal AntiInflammatory Drugs (NSAIDS). Cooper states that for dental pain, NSAIDS are extremely effective. He also suggests that if clinically possible, pretreatment doses with these agents will enhance their therapeutic effect.(22) NSAIDS like ibuprofen block the cyclooxygenase enzymes. There are two isoforms of this enzyme: COX-1 and COX-2. This blockage prevents the conversion of arachidonic acid to prostaglandins. An analgesic effect will take place but there are also other effects like gastrointestinal toxicity (bleeding, ulceration, and perforation).(23) Some common NSAIDS include ibuprofen, naproxen, ketoprofen, flurbiprofen, etodolac, and ketorolac. There have been many studies evaluating NSAIDS as to their efficacy at controlling orofacial pain. Ibuprofen in doses of $200 \mathrm{mg}-400 \mathrm{mg}$ were demonstrated to be superior to placebo in a single dose.(24) In a study done by Menke et al. they found that prophylactic ibuprofen significantly reduced post endodontic pain at 4 and 8 hrs after initiation of root canal therapy, when compared to etodolac and a placebo.(25) Torabinejad et al. compared multiple medications and found that ibuprofen, ketoprofen , erythromycin base, penicillin and methylprednisone plus penicillin were more effective than placebo within the first 48 hours following complete instrumentation of canals.(26)

Traditional NSAIDS block COX-1 and COX-2 enzymes and by doing this unwanted side effects can result. This is especially true with long term use. By inhibiting COX-1 you inhibit the enzyme that is responsible for producing prostaglandins with homeostatic functions. For example, the prostaglandins that are responsible for gastric mucosal integrity and protection are blocked and gastric irritation can result. In a study done by Langman et al. they looked at 1144 patients admitted to the hospital for NSAID related peptic ulcer bleeding.(27) The use of NSAIDS for three months before admittance to the hospital had been strongly associated with these peptic ulcer bleeds. They found that risks of this type increased with the dose of the NSAID.(28) In another study, Rodriguez and Jick evaluated a population-based retrospective case-control study in the United Kingdom. They assessed the risk of upper gastrointestinal bleeding with the use of various NSAIDS. They found the risk 
was greater for higher doses and azapropazone and piroxicam had the highest risk of upper GI bleeding.(29) Along with gastrointestinal toxicity, other side effects are associated with NSAID use. Platelet function can also be impaired because of inhibition of thromboxane, a potent aggregating agent.(30) Patients on aspirin therapy for cardiovascular risks and also taking another NSAID such as ibuprofen or naproxen may have a decreased cardioprotective effect of the aspirin.

Selective COX-2 inhibitors have an advantage over traditional NSAIDS because they spare the COX-1 enzyme, thus decreasing the side effects that are usually seen by inhibiting this enzyme. COX-2 inhibition retains anti-inflammatory activity but decreases the risks of GI toxicity and bleeding.(31) They selectively inhibit only the COX-2 isoform of the COX enzyme and have minimal effect on the COX-1 isoform. The COX-2 enzyme is not found in platelets and therefore selective NSAIDS do not affect platelet function at usual dosages. Selective COX-2 inhibition may be the best choice for long term anti-inflammatory analgesia (greater than 3 months).(32) Scheiman studied the gastroduodenal safety of cyclooxygenase2 inhibition. He found out of 39,000 rheumatoid or osteoarthritis patients, two COX-2 inhibitors, Celecoxib and Rofecoxib, had significantly lower rates of GI-related adverse events than those taking a nonselective NSAID.(33)

Although better for GI toxicity and bleeding, COX-2 inhibitors do have some side effects. Renal effects are similar to that of other NSAIDS. Caution needs to be taken in patients with congestive heart failure, cirrhosis or volume depletion because it can lead to renal ischemia and renal insufficiency. Cardiovascular events are also similar to that of traditional NSAIDS.(34) Patients allergic to aspirin should avoid both nonselective and selective NSAIDS.

Along with decreasing unwanted side effects with COX-2 inhibition, these agents are very effective at controlling pain. Oral surgery models using COX-2 inhibitors have demonstrated their efficacy. Malmstrom et al. studied patients that had two or more third molar extractions and found the analgesic effect of rofecoxib $50 \mathrm{mg}$ was superior to that of celecoxib $200 \mathrm{mg}$ and similar to ibuprofen of $400 \mathrm{mg}$.(35) Rofecoxib also provided greater than 24 hours of analgesia. Ibuprofen provided 9 hours of analgesia and celecoxib for 5 hours.(36) Ciconnetti et al. performed a detailed review of the literature regarding COX-2 inhibition and post-oral surgery pain. They found COX-2 inhibitors provided similar 
analgesia as traditional NSAIDS but are preferable in patients taking aspirin and patients who are at increased risk of GI complications. They also found that selective NSAIDS displayed a longer duration of analgesia than traditional NSAIDS.(37)

Examples of specific COX-2 inhibitors are celecoxib and rofecoxib. These are considered $1^{\text {st }}$ generation COX-2 inhibitors. Celecoxib was found to have a slower onset of action when compared to ibuprofen.(38) Barden et al. found that a single dose of oral celecoxib, $200 \mathrm{mg}$, is an effective means of post-operative pain relief, similar to that of aspirin 600-650 mg and paracetamol 1000mg.(39) Rofecoxib is another COX-2 inhibitor that has been studied in the literature. Morrison et al. assessed the analgesic efficacy of rofecoxib over a 24 hour period for post-oral surgery patients. Rofecoxib 50 mg once daily was as effective as ibuprofen $400 \mathrm{mg}$ in the treatment of post-dental surgery pain and demonstrated a longer duration of action.(40) Moore, in an unpublished thesis found there was no difference in controlling post-endodontic pain between rofecoxib and ibuprofen.(41)

Valdecoxib is a newer selective COX-2 inhibitor. It is considered a $2^{\text {nd }}$ generation COX-2 agent. These newer $2^{\text {nd }}$ generation coxibs have a several fold higher COX-2 selectivity than the $1^{\text {st }}$ generation of coxibs.(7) Stichtenoth and Frolich reviewed these $2^{\text {nd }}$ generation COX-2 inhibitors and found that valdecoxib is rapidly absorbed after oral ingestion with a half life of 8-11 hours. It is metabolized by the liver by the CYP450 isoenzyme CYP3A4. In pain control studies they found that a dose of 20-40 mg as a single dose or twice daily is as effective or superior to ibuprofen, diclofenac, ketorolac, rofecoxib, tramadol, or oxycodone/acetaminophen.(7) Along with analgesic efficacy, they found the incidence of gastroduodenal ulcers in patients receiving 10-20mg of valdecoxib daily was significantly lower than observed with naproxen $500 \mathrm{mg}$, two times a day, and ibuprofen 800 mg, 3 times a day.(7) Chavez and DeKorte performed an extensive review of valdecoxib. Valdecoxib was approved by the FDA in November of 2001. It has been shown to be effective at controlling pain and inflammation associated with rheumatoid and osteoarthritis. It has also shown to be effective at controlling pain associated with dysmenorrhea and postoperative pain.(42) As with any drug, safety and tolerance including side effects have been addressed with the use of valdecoxib. There has been emphasis on cardiovascular events because of the potential for COX-2 inhibitors to decrease production of prostacyclin, a vasodilator and inhibitor of platelet aggregation. No dose of valdecoxib was associated with 
a significant exacerbation of existing hypertension.(43) Chavez also found that $40 \mathrm{mg}$ of Valdecoxib did not affect platelet aggregation or bleeding time. GI discomfort was also reduced when compared to naproxen, ibuprofen, or diclofenac sodium. They also made recommendations on who should avoid using COX-2 inhibitors like valdecoxib. Patients with renal problems, fluid retention or heart failure, asthma, or allergy to aspirin, allergy to sulfa, patients with hepatic disease, or acute peptic ulcer disease should not use COX-2 inhibitors.(44)

When comparing valdecoxib and rofecoxib in relieving pain associated with oral surgery, Fricke et al. found that patients receiving valdecoxib experienced a significantly quicker onset of analgesia, significantly improved pain relief, and lower pain intensity compared with patients receiving rofecoxib.(45) Desjardins et al. examined a single preoperative dose of valdecoxib at relieving post-oral surgery and bunionectomy pain. Patients received a single pre-operative dose of $10 \mathrm{mg}$ (oral surgery only), 20, 40, or $80 \mathrm{mg}$ of valdecoxib. Analgesic efficacy was assessed over 24 hour post-operative period. They found that all doses of valdecoxib were well tolerated with no clinically significant treatment related GI, renal, or platelet adverse events. They concluded that valdecoxib provides well tolerated and effective analgesia for mild to moderate post-operative pain.(46)

COX-2 selective inhibitors are significantly more expensive than nonselective NSAIDS but their advantages may justify the cost.(47) For single pre-operative dosing to control post-operative pain and inflammation, cost may not be a factor.

Evaluating and measuring pain has been examined using several different methods. Scott and Huskisson found the most effective method of analyzing pain and relief of pain was the visual analog and graphic rating scales.(48) Seymour found the $10 \mathrm{~cm}$ visual analog scale was more sensitive than other pain scales and could discriminate between small changes in pain intensity.(49) 


\section{CHAPTER III}

\section{MATERIALS AND METHODS}

\section{Sample Description}

This study involved 19 patients who required endodontic therapy. Each patient was registered and treated at West Virginia University School of Dentistry Endodontic Clinic. Each patient involved in the study was at least 18 years of age. A consent form and medical history form was completed for every patient. History of any of the following conditions excluded the patient from being involved in the study: Mitral valve prolapse, rheumatic heart disease, myocardial infarction, stroke, artificial heart valves or joints, untreated hypertension, hyperthyroidism, hepatitis, epilepsy, bleeding disorders, kidney problems, liver problems, stomach ulcers, pregnancy, current use of antibiotics or pain medications, current use of any kind of medications contraindicated with the use of NSAIDS, allergy to sulfa drugs or history of allergy to NSAIDS, history of rashes, alcoholism, lupus, patients taking coumadin or other anticoagulant, and patients allergic to codeine. All patients were diagnosed with preoperative periapical pain. They also had a pulpal diagnosis of necrotic or irreversible pulpitis. The patients were treated by endodontic residents at WVU SoD. The patients were required to pay the WVU fee for emergency access of the tooth. The patients were not charged for the medication provided and were reimbursed $\$ 15.00$ for completing and returning the stamped pain survey.

\section{Research Design}

This study assessed the ability of a pre-operative oral dose of valdecoxib to reduce post-endodontic pain when compared to ibuprofen. Visual analog scales were used to collect data over time. The need for additional medication was also evaluated. The data was 
analyzed to determine if any difference existed between valdecoxib and ibuprofen and their ability to decrease post-endodontic treatment pain.

Clinical Exam: Informed Consent and a medical history were obtained and a clinical exam was performed. The exam included a percussion test, a cold test (endo-ice), periodontal probing, mobility assessment and palpation. All signs and symptoms (past and present), were noted. A pulpal and periapical diagnosis of the offending tooth was determined. See flow charts (Appendix D).

Visual Analog Scale: Prior to administration of anesthetic and the medication, each patient recorded his/her initial pain perception on the pain survey (Appendix C). Pain intensity was measured using a 100mm visual analog scale (VAS). The scale was from zero to one hundred, zero was “no pain” and one hundred was "pain so severe you can’t stand it”. The pain survey included a VAS for: immediately after the root canal treatment, 4 hrs, 8 hrs, 12 hrs, 24 hrs, 48 hrs and 72 hrs after root canal therapy was initiated. The pain survey also included an area to indicate if additional medication was required at each corresponding time interval.

\section{Methodology}

Nineteen patients were involved in this study. The medications that were used were reported as safe and effective for pain and inflammation by their manufacturers. Upon approval from the Institutional Review Board of West Virginia University (Appendix A), a consent form (Appendix B) was signed by all patients prior to treatment. Patients consented to a single-blind, random, pre-operative oral administration of either 600mg ibuprofen or 20 mg of valdecoxib. Before anesthesia, the patient entered his/her initial pain perception on the pain scale. Local anesthetic was administered and endodontic access was achieved under rubber dam isolation. Cleaning and shaping of the root canal system was accomplished in the following manner: Negotiation of canals with Flex-o-files \#8, \#10, \#15, \#20, \#25 to a radiographic estimate of working length. Gates Glidden burs \#2-4 were used to enlarge the canal orifice and irrigation with 5.25\% sodium hypochlorite was used throughout the procedure. Canal lubricant like RC Prep, a chelating agent, was also used on the files. The 
canals were dried with paper points. Calcium hydroxide paste (Pulp Dent) was placed in each canal and then IRM was used as the temporary filling material. Occlusion was evaluated and reduced as necessary. Each patient was scheduled with a return appointment for root canal therapy completion and emergency phone numbers were given.

The patient then recorded his/her pain perception on the pain survey immediately after the procedure. They were also instructed to do this at the 4, 8, 12, 24, 48, and 72 hour time intervals after root canal therapy was initiated. A rescue medication of $5 \mathrm{mg}$ hydrocodone/500 acetaminophen was given to each patient with the instructions to take it if they experience break-through pain. They were advised to take the rescue medication only if needed and to record the time it was taken on the pain survey.

\section{Data Collection}

The VAS values were measured with a standard millimeter ruler and recorded on the data collection sheet. Additional data was also recorded on the data collection sheet like: Subject \#, Medication \#, Pulpal diagnosis, Periapical diagnosis, extra medication requirement and gastro-intestinal upset.

\section{Statistical Analysis}

Data analysis was performed on three sets of data. The first set compared each medication and corresponding VAS values for each patient at each time interval. The second set compared the need for extra medication with regard to pulpal and periapical diagnosis.

The third set compared the extra rescue medication requirement with each given medication. The first set of data was analyzed using a two-factor ANOVA Test $(\mathrm{P}<0.05)$. The second and third sets were analyzed using a Chi-Square Test $(\mathrm{P}<0.05)$.

\section{Equipment and Materials}

- Valdecoxib 20 mg (Pfizer Inc., New York, NY)

- Ibuprofen 600 mg (Whitehall-Robbins, Madison, NJ)

- Individuals receiving conventional root canal therapy

- Local Anesthetic (Astra, Westborough, MA)

- $\quad$ Flex-O-Files (Dentsply, Milford, DE) 
- Gates-Glidden burs \#2, \#3, and \#4 (Dentsply, Milford, DE)

- Standard WVU School of Dentistry Endodontic set-up

- Dental Dam (Coltene/Whaledent Inc., Mahwah, NJ)

- $5.25 \%$ sodium hypochlorite (The Clorox Co., Oakland, CA)

- IRM temporary material

- Endodontic paper points (Dentsply, Milford, DE)

- $\quad$ Endo-Ice (Hygenic, Akron, $\mathrm{OH}$ )

- $\quad$ Ektaspeed Plus dental film (Kodak, Rochester, NY)

- Standard millimeter ruler

- Medical history form

- Pain survey including $10 \mathrm{~cm}$ (100 mm) visual analog scale 


\section{CHAPTER IV}

\section{RESULTS AND DISCUSSION}

\section{RESULTS}

Nineteen subjects participated in the study. Three subjects did not return the pain survey so data was analyzed for sixteen subjects. Table 1 displays the data collection sheet. Eight subjects received ibuprofen (six returned the survey) and eleven received valdecoxib (ten returned the survey). Each subject recorded his or her perceived pain on the VAS for each specified time interval: initial, immediately after, 4 hrs, 8 hrs, 12 hrs, 24 hrs, 48 hrs, and 72 hrs after initiation of the root canal. Zero millimeters corresponded to "no pain” and 100 millimeters corresponded to “pain so severe you can’t stand it” (See Appendix C). Seven females and twelve males were involved in the study. The subjects who entered the study were not taking antibiotics or pain medications such as NSAIDS or narcotics. Each subject presented with periapical pain. Both a pulpal and a periapical diagnosis were determined for each subject. Of the pulpal diagnoses, five subjects had an Irreversible Pulpitis and eleven had a Necrotic Pulp. Of the periapical diagnoses, eight had Acute Apical Periodontitis and eight subjects had a Phoenix Abscess. Seven subjects reported needing the additional pain medication following initiation of endodontic therapy.

Figure 1 shows comparison of each medication and its effectiveness at controlling pain at each time interval. Statistical analysis showed that there was no significant difference between ibuprofen and valdecoxib at controlling post-endodontic pain (P-value=0.2137). They both reduced pain over time. Table 3 shows means and standard deviations for each medication at each time interval following endodontic therapy.

Table 4 and Figure 2 display the number of subjects who were diagnosed with each pulpal diagnosis. Also displayed is the number of subjects who required additional medication for post-endodontic pain. Five subjects presented with an Irreversible Pulpitis and one of them required extra medication for pain. Eleven subjects presented with a 
Necrotic Pulp and six of them required extra pain medication. A Chi-Square analysis showed no significant difference between pulpal diagnosis and the need for additional medication $(\mathrm{P}=0.1967)$.

Table 5 and Figure 3 display the number of subjects who were diagnosed with each periapical diagnosis and the need for extra pain medication. Eight subjects had Acute Apical Periodontitis and of those three required extra medication. Eight subjects had Phoenix Abscess and four of them needed extra pain medication. A Chi-Square analysis showed no significant difference between periapical diagnosis and the need for additional pain medication ( $\mathrm{P}=0.6143)$.

Of the seven subjects who needed additional pain medication, four had received valdecoxib and three had received ibuprofen. A Chi-Square analysis showed no significant difference between the extra medication requirement and which medication the subjects received $(\mathrm{P}=0.6966)$.

Of the six subjects who received ibuprofen, three needed additional medication at some point after initiation of root canal therapy. Of the ten subjects who received valdecoxib, four required additional medication. 
Table 1. Data Collection Sheet

TABLE 1

\section{Data Collection Sheet}

\begin{tabular}{|c|c|c|c|c|c|c|c|c|c|c|c|c|c|}
\hline $\begin{array}{l}\mathrm{Pt} \\
\#\end{array}$ & $\begin{array}{c}\text { Med } \\
\#\end{array}$ & Pulp Dx & $\begin{array}{l}\text { PA } \\
\text { Dx }\end{array}$ & \begin{tabular}{|c} 
Initi \\
al
\end{tabular} & $\begin{array}{l}\text { Imm } \\
\text { After }\end{array}$ & $\begin{array}{c}4 \\
\mathrm{Hrs}\end{array}$ & $\begin{array}{c}8 \\
\mathrm{Hrs}\end{array}$ & $\begin{array}{c}12 \\
\mathrm{Hrs}\end{array}$ & $\begin{array}{c}24 \\
\mathrm{Hrs}\end{array}$ & $\begin{array}{c}48 \\
\text { Hrs }\end{array}$ & $\begin{array}{c}2 \\
\mathrm{Hrs}\end{array}$ & $\begin{array}{c}X \\
\text { Med } \\
s\end{array}$ & GI Upset \\
\hline & & & & & & & & & & & & & \\
\hline 1 & b & 2 & 1 & & & & & & & & & & \\
\hline 2 & $\mathrm{a}$ & 2 & 1 & 28 & 1 & 1 & 3 & 2 & 0 & 1 & 1 & 0 & 0 \\
\hline 3 & $\mathrm{a}$ & 1 & 2 & 61 & 0 & 2 & 6 & 5 & 0 & 0 & 0 & 0 & 0 \\
\hline 4 & $b$ & 1 & 2 & 21 & 0 & 0 & 0 & 0 & 0 & 0 & 0 & 0 & 0 \\
\hline 5 & a & 1 & 2 & & & & & & & & & & \\
\hline 6 & $b$ & 1 & 1 & 66 & 23 & 26 & 33 & 65 & 69 & 9 & 5 & 1 & 0 \\
\hline 7 & $b$ & 1 & 2 & 59 & 3 & 15 & 17 & 18 & 14 & 6 & 0 & 1 & 0 \\
\hline 8 & $b$ & 2 & 1 & 69 & 0 & 0 & 0 & 0 & 0 & 0 & 0 & 0 & 0 \\
\hline 9 & $b$ & 1 & 1 & 62 & 7 & 56 & 48 & 40 & 34 & 31 & 6 & 0 & 0 \\
\hline 10 & $b$ & 1 & 2 & 80 & 13 & 5 & 32 & 29 & 4 & 9 & 0 & 0 & 0 \\
\hline 11 & $b$ & 1 & 2 & 69 & 46 & 33 & 27 & 23 & 47 & 59 & 67 & 1 & 0 \\
\hline 12 & $b$ & 1 & 2 & 68 & 6 & 9 & 8 & 7 & 9 & 11 & 11 & 0 & 0 \\
\hline 13 & $\mathrm{a}$ & 1 & 2 & 82 & 3 & 4 & 5 & 61 & 4 & 0 & 0 & 1 & 0 \\
\hline 14 & $b$ & 2 & 1 & 62 & 0 & 19 & 28 & 0 & 20 & 26 & 6 & 1 & 0 \\
\hline 15 & $a$ & 1 & 1 & 42 & 3 & 16 & 3 & 3 & 2 & 21 & 16 & 1 & 0 \\
\hline 16 & $a$ & 2 & 1 & 63 & 6 & 5 & 5 & 29 & 24 & 27 & 22 & 0 & 0 \\
\hline 17 & $a$ & 1 & 2 & 95 & 47 & 31 & 28 & 20 & 73 & 35 & 46 & 1 & 0 \\
\hline 18 & a & 2 & 1 & & & & & & & & & & \\
\hline 19 & $b$ & 2 & 1 & 66 & 4 & 4 & 15 & 0 & 16 & 4 & 0 & 0 & 0 \\
\hline & & & & & & & & & & & & & \\
\hline & & & & & & & & & & & & & \\
\hline & \multicolumn{6}{|c|}{ The data shaded in blue were not analyzed } & & & & & & & \\
\hline & & & & & & & & & & & & & \\
\hline
\end{tabular}


Table 2. Data Collection Sheet Legend

TABLE 2

Data Collection Sheet Legend

\begin{tabular}{|l|l|l|}
\hline MED & a=lbuprofen & b=valdecoxib \\
\hline Pulp Dx & 1=Necrotic & 2=Irrev. Pulpitis \\
\hline PA Dx & 1=AAP & 2=Phoenix abscess \\
\hline X-MEDS & $0=$ No & 1=Yes \\
\hline GI UPSET & $0=$ No & 1=Yes \\
\hline
\end{tabular}




\section{FIGURE 1}

Experimental Medications and Pain Relief over Time

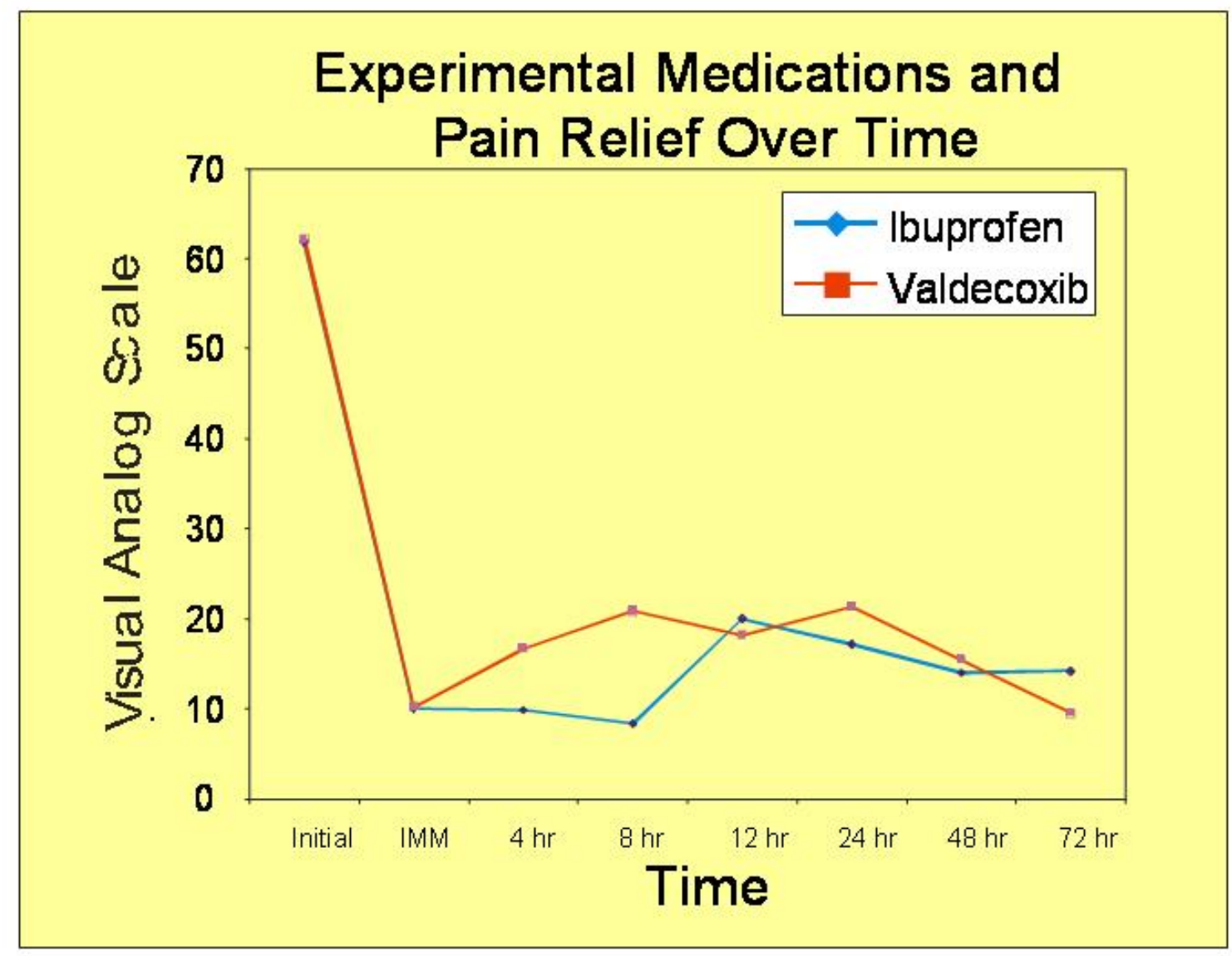

Figure 1. Experimental Medication and Pain Relief Over Time 
Table 3. Means and Standard Deviations

TABLE 3

\section{Means and Standard Deviations}

\begin{tabular}{|c|c|c|c|c|}
\hline Medication & Time & Total & Mean & Standard \\
\hline & & & & Deviation \\
\hline & & & & 24.7 \\
\hline ibuprofen & initial & $371 / 6$ & 61.83 & 18.2 \\
\hline & immed after & $60 / 6$ & 9.83 & 11.7 \\
\hline & $4 \mathrm{hrs}$ & $59 / 6$ & 8.33 & 9.7 \\
\hline & $8 \mathrm{hrs}$ & $50 / 6$ & 20 & 22.8 \\
\hline & $12 \mathrm{hrs}$ & $120 / 6$ & 17.17 & 28.8 \\
\hline & $24 \mathrm{hrs}$ & $103 / 6$ & 14 & 15.6 \\
\hline & $48 \mathrm{hrs}$ & $84 / 6$ & 14.17 & 18.2 \\
\hline & $72 \mathrm{hrs}$ & $85 / 6$ & 62.2 & 15.6 \\
\hline valdecoxib & initial & $622 / 10$ & 10.2 & 14.5 \\
\hline & immed after & $102 / 10$ & 16.7 & 17.7 \\
\hline & $4 \mathrm{hrs}$ & $167 / 10$ & 20.8 & 15.6 \\
\hline & $8 \mathrm{hrs}$ & $208 / 10$ & 18.2 & 21.7 \\
\hline & $12 \mathrm{hrs}$ & $182 / 10$ & 21.3 & 22.5 \\
\hline & $24 \mathrm{hrs}$ & $213 / 10$ & 15.5 & 18.4 \\
\hline & $48 \mathrm{hrs}$ & $155 / 10$ & 9.5 & 20.6 \\
\hline
\end{tabular}


Table 4. Pulpal Diagnosis and Additional Medication

\section{TABLE 4}

Pulpal Diagnosis and Additional Medication

\begin{tabular}{|l|c|c|}
\hline Pulpal Diagnosis & Subjects & Extra Meds \\
\hline Necrotic & 11 & 6 \\
\hline Irreversible Pulpitis & 5 & 1 \\
\hline
\end{tabular}




\section{FIGURE 2}

\section{Pulpal Diagnosis and Extra Medication}

Figure 2. Pulpal Diagnosis and Extra Medication

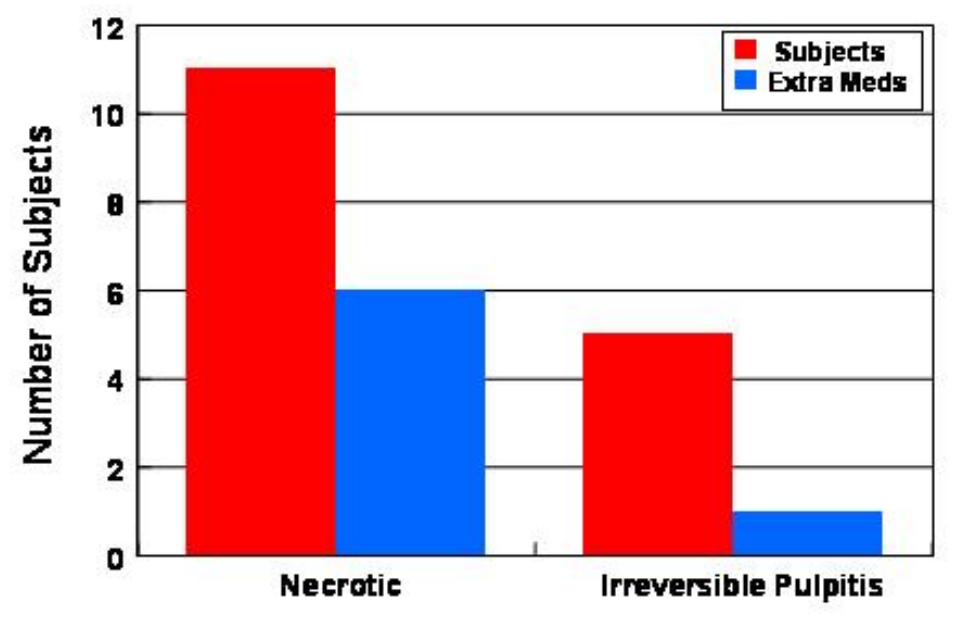

Pulpal Diagnosis/Extra Medications 
Table 5. Periapical Diagnosis and Additional Medication

\section{TABLE 5}

Periapical Diagnosis and Additional Medication

\begin{tabular}{|l|c|c|}
\hline Periapical Diagnosis & Subjects & Extra Meds \\
\hline Phoenix Abscess & 8 & 4 \\
\hline AAP & 8 & 3 \\
\hline
\end{tabular}




\section{FIGURE 3}

\section{Periapical Diagnosis and Extra Medication}

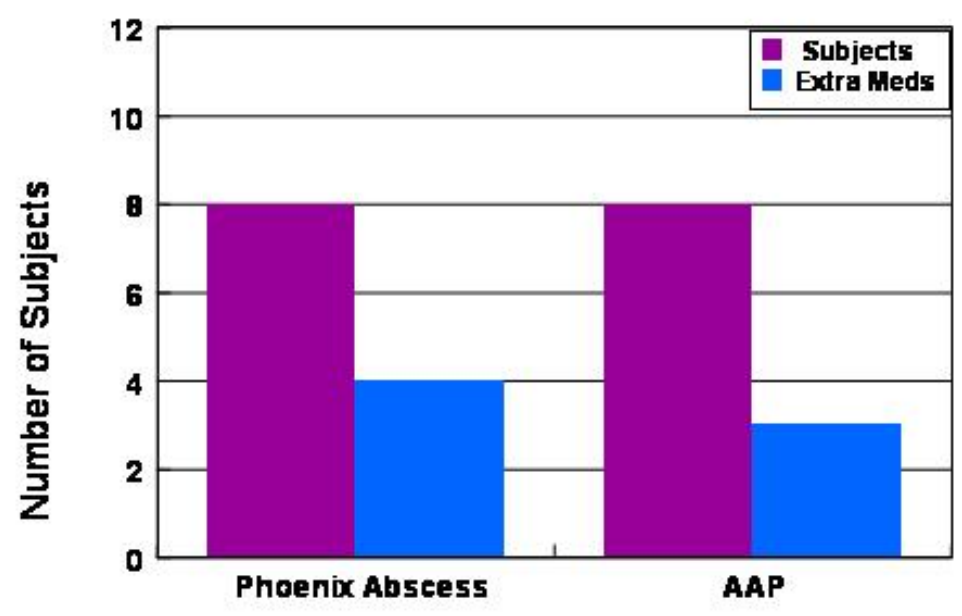

Periapical Diagnosis/Extra Medications

Figure 3. Periapical Diagnosis and Extra Medication 


\section{DISCUSSION}

Controlling pain has been successfully managed by NSAIDS for many years. The ultimate goal of these drugs is to block the cyclooxygenase enzymes that convert arachidonic acid to prostaglandins.(50) It is these prostaglandins that contribute to more pain and inflammation. Ibuprofen, which is the prototype of the NSAID drug class, has demonstrated analgesic efficacy over a range from 200-800 mg with duration of action of 4-6 hours.(51) NSAIDS like ibuprofen have been studied for treating pain associated with inflammation in endodontic applications.(41;52-54)

A newer class of NSAIDS, COX-2 Inhibitors, has also been studied at controlling acute pain. These drugs selectively block only the COX-2 enzyme which leaves the protective action of prostaglandins in the stomach and kidney alone. Valdecoxib is one of these drugs and has shown to be effective at controlling dental pain.(7;55-57) Valdecoxib has an effective dose range of 10-80 mg with duration of action of 8-11 hours.(58)

In this clinical study, valdecoxib was compared to ibuprofen to evaluate its effectiveness at controlling post-endodontic pain. Both ibuprofen and valdecoxib were found to be equally effective at controlling post-endodontic pain. Nineteen subjects were enrolled in this study. All subjects had periapical pain. The results indicated that neither the pulpal nor the periapical diagnosis played a role in the need for additional pain medication. Approximately nine of the sixteen subjects continued to have pain over time. This could be attributed to many factors. One reason for this is that patients who have moderate to severe pre-operative pain are likely to have moderate to severe post-operative pain.(1;59) The subjects who continued to have pain in this study all had high VAS values initially and continued to have pain regardless of which medication they had received. The inflammatory process that is already in place does not immediately subside when root canal therapy is rendered. The source of the inflammation (necrotic and or inflamed pulp tissue) has been removed but the inflammatory mediators take time to dissipate.

Another factor for continued pain reported by some subjects could be attributed to endodontic therapy itself. Instrumentation of the root canal can cause post-operative pain. Seltzer and Naidorf stated that when endodontic therapy is performed, new irritants in the form of medicaments, irrigating solutions, and chemically altered tissue proteins can be introduced into the already inflamed tooth.(60) They also state that changes in periapical 
tissue pressure, microbial factors, immunological phenomena, and the nature of the inflammatory process alone can cause exacerbation of pain.(60)

Pain studies in general are difficult to measure. Pain perception is subjective and can vary greatly from person to person. Roane et al. stated that pain studies are difficult due to the reliability of values placed on the entity of pain.(61) Fear plays a role in the perception of pain. The fear of dentists and/or dental procedures, anxiety, apprehension, and other psychological factors influence the patient's pain perception and reaction threshold.(60) Endodontic therapy, in particular, appears to be painful to many patients either because of previous experiences or from derogatory comments from others. These induced anxieties intensify and perpetuate painful episodes.(60)

The manufacturer of valdecoxib, (Pfizer Inc.,), recommends a $40 \mathrm{mg}$ dose initially to control acute pain and then 20-40 mg two times a day for 48 hours. Due to inability to control patient adherence with this dosing schedule this was not feasible in this study. This could explain why we did not see more effective pain control for valdecoxib. Another possible explanation for seeing little difference in efficacy between ibuprofen and valdecoxib was sample size. On April 7, 2005 the Food and Drug Administration removed valdecoxib from the market due to unwanted side effects shown with chronic use. Skin and cardiovascular complications were cited as reasons for this removal. We may have seen larger differences between ibuprofen and valdecoxib if more subjects had been involved in the study.

It has been shown that a pre-operative dose of an NSAID has been effective at controlling post-operative pain.(54;62-66) This current study evaluated a one-time preoperative administration of either $600 \mathrm{mg}$ ibuprofen or $20 \mathrm{mg}$ valdecoxib and their ability to control post-endodontic pain. Results showed no statistically significant differences between the two medications at any of the time intervals. Of the subjects who required extra pain medication, the mean time to rescue medication for valdecoxib was 28 hours. The mean time to rescue medication for ibuprofen was 23 hours. Due to the longer duration of action of valdecoxib (8-11 hours) versus 4-6 hours for ibuprofen, these findings were perplexing. However, patient recording of the exact time they needed extra medication may have been inaccurate. The dosing of valdecoxib in this study may also have played a role for this finding. 
The cost of valdecoxib is significantly more than for ibuprofen and would require a prescription. Thirty tablets of ibuprofen $(600 \mathrm{mg})$ is approximately $\$ 12.49$. Thirty tablets of valdecoxib (20mg) is $\$ 115.27$. This averages out to $\$ 0.42$ per ibuprofen tablet and $\$ 3.84$ per valdecoxib tablet. This is a significant cost difference and may play a role in which pain reliever a patient chooses to use.

It is interesting to note that in this study, no gastrointestinal upset was reported by any of the subjects for either medication at any time interval. This is likely due to the fact that stomach irritation is usually associated with chronic use of NSAIDS not with single dosing.

This study found that neither $20 \mathrm{mg}$ valdecoxib nor $600 \mathrm{mg}$ ibuprofen were more effective than the other at controlling post-endodontic pain. Ibuprofen is a safe and effective drug choice to treat acute dental pain associated with inflammation. Patients who may have a medical contraindication for using a traditional NSAID such as a bleeding disorder, stomach ulcer, or gastro-intestinal sensitivity may need a selective COX-2 inhibitor as an alternative choice for pain control. Valdecoxib could have been one such choice but recent suspension of drug availability has eliminated this as a possible option. 


\section{CHAPTER V SUMMARY AND CONCLUSIONS}

\section{SUMMARY}

The purpose of this study was to compare the efficacy of pain control between ibuprofen and valdecoxib when administered pre-operatively. It was hypothesized that there would be no difference between ibuprofen and valdecoxib in controlling post-endodontic treatment pain. It was assumed that patients who were experiencing pre-operative pain were likely to experience post-operative pain after initiation of root canal therapy.

Nineteen subjects participated in this clinical study. Each subject was diagnosed with periapical pain and needed root canal therapy. They rated their pain on a pain survey containing a visual analog scale (VAS) and were given $600 \mathrm{mg}$ ibuprofen or $20 \mathrm{mg}$ valdecoxib before treatment was initiated. The VAS was then taken home and subjects were instructed to rate their post-operative pain at the specified time intervals. Three subjects did not return the pain survey so data from sixteen subjects was analyzed.

It was determined there was no significant difference between ibuprofen and valdecoxib at controlling post-endodontic pain at any of the time intervals. They both were equally effective in controlling pain after root canal therapy was initiated. There were also no statistically significant differences between pulpal or periapical diagnoses and the need for additional medication. It was also found that a significant difference did not exist between the types of medication initially received and the need for additional medication.

This study determined that ibuprofen and valdecoxib are effective in controlling postendodontic pain and that neither is superior to the other when statistically compared. Ibuprofen is a safe and effective medication which is relatively inexpensive. It has and will continue to be a common medication used for pain. If valdecoxib were available for use it could be an alternative drug choice for patients unable to take traditional NSAIDS. 


\section{CONCLUSIONS}

This clinical study showed no significant difference between ibuprofen and valdecoxib and their abilities to control post-endodontic pain when administered preoperatively. 


\title{
REFERENCE LIST
}

\author{
Reference List
}

1. Okeefe EM. Pain in Endodontic Therapy:Preliminary Study. J.Endod. 1976;2:315-9.

2. Trowbridge H.O, Emling R. C., Inflammation. A Review of the Process. 5th edition ed. Carol Stream, Illinois: Quintessence Publishing Co, Inc; 1997.

3. Chavez, M. L. and DeKorte, C. J. Valdecoxib: a Review. Clin.Ther. 2003;25(3):817-51.

4. Chavez, M. L. and DeKorte, C. J. Valdecoxib: a Review. Clin.Ther. 2003;25(3):817-51.

5. Dionne, R. Pharmacologic Treatment of Acute and Chronic Orofacial Pain. Oral and Maxillofacial Surgery Clinics of North America 2000;12(2):309-20.

6. Dionne, R. Pharmacologic Treatment of Acute and Chronic Orofacial Pain. Oral and Maxillofacial Surgery Clinics of North America 2000;12(2):309-20.

7. Stichtenoth, D. O. and Frolich, J. C. The Second Generation of COX-2 Inhibitors: What Advantages Do the Newest Offer? Drugs. 2003;63(1):33-45.

8. $\quad$ Fricke, J., Varkalis, J., Zwillich, S., Adler, R., Forester, E., Recker, D. P., and Verburg, K. M. Valdecoxib Is More Efficacious Than Rofecoxib in Relieving Pain Associated With Oral Surgery. Am.J.Ther. 2002;9(2):89-97.

9. SELTZER, S., BENDER, I. B., and Eherenrich, J. Incidence and Duration of Pain Following Endodontic Therapy. Relationship to Treatment With Sulfonamides and to Other Factors. Oral Surg.Oral Med.Oral Pathol. 1961;14:74-82.

10. Harrison, J. W., Baumgartner, J. C., and Svec, T. A. Incidence of Pain Associated With Clinical Factors During and After Root Canal Therapy. Part 2.

Postobturation Pain. J.Endod. 1983;9(10):434-8.

11. Harrison, J. W., Baumgartner, J. C., and Svec, T. A. Incidence of Pain Associated With Clinical Factors During and After Root Canal Therapy. Part 2.

Postobturation Pain. J.Endod. 1983;9(10):434-8. 
12. Soltanoff, W. A Comparative Study of the Single-Visit and the Multiple-Visit Edodontic Procedure. J.Endod. 1978;4(9):278-81.

13. Roane, J. B., Dryden, J. A., and Grimes, E. W. Incidence of Postoperative Pain After Single- and Multiple-Visit Endodontic Procedures. Oral.Surg.Oral.Med.Oral.Pathol. 1983;55(1):68-72.

14. Trope, M. Flare-Up Rate of Single-Visit Endodontics. Int.Endod.J. 1991;24(1):24-6.

15. Siqueira, J. F., Jr. Microbial Causes of Endodontic Flare-Ups. Int.Endod.J. 2003;36(7):453-63.

16. Siqueira, J. F., Jr. Microbial Causes of Endodontic Flare-Ups. Int.Endod.J. 2003;36(7):453-63.

17. Balaban, F. S., Skidmore, A. E., and Griffin, J. A. Acute Exacerbations Following Initial Treatment of Necrotic Pulps. J.Endod. 1984;10(2):78-81.

18. Dionne, R. Relative Efficacy of Selective COX-2 Inhibitors Compared With Over-the-Counter Ibuprofen. Int.J.Clin.Pract.Suppl 2003;(135):18-22.

19. Torabinejad, M. and Bakland, L. K. Prostaglandins: Their Possible Role in the Pathogenesis of Pulpal and Periapical Diseases, Part 2. J.Endod. 1980;6(10):76976.

20. Cooper, S. A. Treating Acute Pain: Do's and Don'Ts, Pros and Cons. J.Endod. 1990;16(2):85-91.

21. Cooper, S. A. Treating Acute Pain: Do's and Don'Ts, Pros and Cons. J.Endod. 1990;16(2):85-91.

22. Cooper, S. A. Treating Acute Pain: Do's and Don'Ts, Pros and Cons. J.Endod. 1990;16(2):85-91.

23. Hutchison, R. Cox-2-Selective NSAIDS. A Review and Comparison With Nonselective NSAIDS. Ameican Journal of Nursing 2004;104(3):52-5.

24. Dionne, R. Pharmacologic Treatment of Acute and Chronic Orofacial Pain. Oral and Maxillofacial Surgery Clinics of North America 2000;12(2):309-20.

25. Menke, E. R., Jackson, C. R., Bagby, M. D., and Tracy, T. S. The Effectiveness of Prophylactic Etodolac on Postendodontic Pain. J.Endod. 2000;26(12):712-5.

26. Torabinejad, M., Cymerman, J. J., Frankson, M., Lemon, R. R., Maggio, J. D., and Schilder, H. Effectiveness of Various Medications on Postoperative Pain Following Complete Instrumentation. J.Endod. 1994;20(7):345-54. 
27. Langman, M. J., Weil, J., Wainwright, P., Lawson, D. H., Rawlins, M. D., Logan, R. F., Murphy, M., Vessey, M. P., and Colin-Jones, D. G. Risks of Bleeding Peptic Ulcer Associated With Individual Non-Steroidal Anti-Inflammatory Drugs. Lancet. 430-1994;343(8905):1075-8.

28. Langman, M. J., Weil, J., Wainwright, P., Lawson, D. H., Rawlins, M. D., Logan, R. F., Murphy, M., Vessey, M. P., and Colin-Jones, D. G. Risks of Bleeding Peptic Ulcer Associated With Individual Non-Steroidal Anti-Inflammatory Drugs. Lancet. 430-1994;343(8905):1075-8.

29. Rodriguez, L and Jick, H. Risk of Upper Gastrointestinal Bleeding and Perforation Associated With Individual Non-Steroidal Anti-Inflammatory Drugs. Lancet 1994;343:769-72.

30. Hutchison, R. Cox-2-Selective NSAIDS. A Review and Comparison With Nonselective NSAIDS. Ameican Journal of Nursing 2004;104(3):52-5.

31. Claria, J. Cyclooxygenase-2 Biology. Curr.Pharm.Des. 2003;9(27):2177-90.

32. Hutchison, R. Cox-2-Selective NSAIDS. A Review and Comparison With Nonselective NSAIDS. Ameican Journal of Nursing 2004;104(3):52-5.

33. Scheiman, J. M. Gastroduodenal Safety of Cyclooxygenase-2 Inhibitors. Curr.Pharm.Des 2003;9(27):2197-206.

34. Hutchison, R. Cox-2-Selective NSAIDS. A Review and Comparison With Nonselective NSAIDS. Ameican Journal of Nursing 2004;104(3):52-5.

35. Malmstrom, K., Daniels, S., Kotey, P., Seidenberg, B. C., and Desjardins, P. J. Comparison of Rofecoxib and Celecoxib, Two Cyclooxygenase-2 Inhibitors, in Postoperative Dental Pain: a Randomized, Placebo- and Active-ComparatorControlled Clinical Trial. Clin.Ther. 1999;21(10):1653-63.

36. Malmstrom, K., Daniels, S., Kotey, P., Seidenberg, B. C., and Desjardins, P. J. Comparison of Rofecoxib and Celecoxib, Two Cyclooxygenase-2 Inhibitors, in Postoperative Dental Pain: a Randomized, Placebo- and Active-ComparatorControlled Clinical Trial. Clin.Ther. 1999;21(10):1653-63.

37. Cicconetti, A., Bartoli, A., Ripari, F., and Ripari, A. COX-2 Selective Inhibitors: a Literature Review of Analgesic Efficacy and Safety in Oral-Maxillofacial Surgery. Oral Surg.Oral Med.Oral Pathol.Oral Radiol.Endod. 2004;97(2):139-46.

38. Dionne, R. Relative Efficacy of Selective COX-2 Inhibitors Compared With Over-the-Counter Ibuprofen. Int.J.Clin.Pract.Suppl 2003;(135):18-22.

39. Barden J, Edwards JE McQuay HJ Moore RA. Single Dose Oral Celecoxib for Postoperative Pain. Cochran Databse Syst.Rev. 2003. 
Ref Type: Internet Communication

40. Morrison, B. W., Christensen, S., Yuan, W., Brown, J., Amlani, S., and Seidenberg, B. Analgesic Efficacy of the Cyclooxygenase-2-Specific Inhibitor Rofecoxib in Post-Dental Surgery Pain: a Randomized, Controlled Trial. Clin.Ther. 1999;21(6):943-53.

41. Moore, Stephen. The Effectiveness of Rofecoxib on Post-endodontic Pain. 2002.

42. Chavez, M. L. and DeKorte, C. J. Valdecoxib: a Review. Clin.Ther. 2003;25(3):817-51.

43. Chavez, M. L. and DeKorte, C. J. Valdecoxib: a Review. Clin.Ther. 2003;25(3):817-51.

44. Chavez, M. L. and DeKorte, C. J. Valdecoxib: a Review. Clin.Ther. 2003;25(3):817-51.

45. Fricke, J., Varkalis, J., Zwillich, S., Adler, R., Forester, E., Recker, D. P., and Verburg, K. M. Valdecoxib Is More Efficacious Than Rofecoxib in Relieving Pain Associated With Oral Surgery. Am.J.Ther. 2002;9(2):89-97.

46. Desjardins, P. J., Shu, V. S., Recker, D. P., Verburg, K. M., and Woolf, C. J. A Single Preoperative Oral Dose of Valdecoxib, a New Cyclooxygenase-2 Specific Inhibitor, Relieves Post-Oral Surgery or Bunionectomy Pain. Anesthesiology 2002;97(3):565-73.

47. Hutchison, R. Cox-2-Selective NSAIDS. A Review and Comparison With Nonselective NSAIDS. Ameican Journal of Nursing 2004;104(3):52-5.

48. Scott, J and Huskisson, E. C. Graphic Representation of Pain. Pain $1976 ; 2: 175-84$.

49. Seymour, R. A. The Use of Pain Scales in Assessing the Efficacy of Analgesics in Post-Operative Dental Pain. Eur.J.Clin.Pharmacol. 1982;23(5):441-4.

50. Cooper, S. A. Treating Acute Pain: Do's and Don'Ts, Pros and Cons. J.Endod. 1990;16(2):85-91.

51. Dionne, R. Relative Efficacy of Selective COX-2 Inhibitors Compared With Over-the-Counter Ibuprofen. Int.J.Clin.Pract.Suppl 2003;(135):18-22.

52. Menke, E. R., Jackson, C. R., Bagby, M. D., and Tracy, T. S. The Effectiveness of Prophylactic Etodolac on Postendodontic Pain. J.Endod. 2000;26(12):712-5. 
53. Torabinejad, M., Cymerman, J. J., Frankson, M., Lemon, R. R., Maggio, J. D., and Schilder, H. Effectiveness of Various Medications on Postoperative Pain Following Complete Instrumentation. J.Endod. 1994;20(7):345-54.

54. Flath R.K, Hicks, M. L., Dionne, R, and Pelleu, G. B. Pain Supression After Pulpectomy With Pre-Operative Flurbiprofen. J.Endod. 1987;13:339-47.

55. Fricke, J., Varkalis, J., Zwillich, S., Adler, R., Forester, E., Recker, D. P., and Verburg, K. M. Valdecoxib Is More Efficacious Than Rofecoxib in Relieving Pain Associated With Oral Surgery. Am.J.Ther. 2002;9(2):89-97.

56. Cicconetti, A., Bartoli, A., Ripari, F., and Ripari, A. COX-2 Selective Inhibitors: a Literature Review of Analgesic Efficacy and Safety in Oral-Maxillofacial Surgery. Oral Surg.Oral Med.Oral Pathol.Oral Radiol.Endod. 2004;97(2):139-46.

57. Desjardins, P. J., Shu, V. S., Recker, D. P., Verburg, K. M., and Woolf, C. J. A Single Preoperative Oral Dose of Valdecoxib, a New Cyclooxygenase-2 Specific Inhibitor, Relieves Post-Oral Surgery or Bunionectomy Pain. Anesthesiology 2002;97(3):565-73.

58. Desjardins, P. J., Shu, V. S., Recker, D. P., Verburg, K. M., and Woolf, C. J. A Single Preoperative Oral Dose of Valdecoxib, a New Cyclooxygenase-2 Specific Inhibitor, Relieves Post-Oral Surgery or Bunionectomy Pain. Anesthesiology 2002;97(3):565-73.

59. Torabinejad, M., Cymerman, J. J., Frankson, M., Lemon, R. R., Maggio, J. D., and Schilder, H. Effectiveness of Various Medications on Postoperative Pain Following Complete Instrumentation. J.Endod. 1994;20(7):345-54.

60. Seltzer.S. and Naidorf, I. Flare-Ups in Endodontics 1. Etiological Factors. J.Endod. 2004;30:476-81.

61. Roane, J. B., Dryden, J. A., and Grimes, E. W. Incidence of Postoperative Pain After Single- and Multiple-Visit Endodontic Procedures. Oral.Surg.Oral.Med.Oral.Pathol. 1983;55(1):68-72.

62. Menke, E. R., Jackson, C. R., Bagby, M. D., and Tracy, T. S. The Effectiveness of Prophylactic Etodolac on Postendodontic Pain. J.Endod. 2000;26(12):712-5.

63. Cooper, S. A. Treating Acute Pain: Do's and Don'Ts, Pros and Cons. J.Endod. 1990;16(2):85-91.

64. Desjardins, P. J., Shu, V. S., Recker, D. P., Verburg, K. M., and Woolf, C. J. A Single Preoperative Oral Dose of Valdecoxib, a New Cyclooxygenase-2 Specific Inhibitor, Relieves Post-Oral Surgery or Bunionectomy Pain. Anesthesiology 2002;97(3):565-73. 
65. Dionne, R. Relative Efficacy of Selective COX-2 Inhibitors Compared With Over-the-Counter Ibuprofen. Int.J.Clin.Pract.Suppl 2003;(135):18-22.

66. Dionne, R, Campbell, R. A., Cooper, S. A., Hall, D. L., and Buckingam, B. Supression of Post-Operative Pain by the Pre-Operative Administration of Ibuprofen in Comparison to Placebo, Acetaminophen, and Acetaminophen Plus Codeine. J.Clin.Pharmacol 1983;23:37-43. 
APPPENDIX A

IRB PROTOCOL APPROVAL 


\section{WestVirginiaUniversity}

Office of Research Compliance

DATE: September 3,2004

This research will be monitored for re-approval annually. APPROVAL PERIOD: July 28, 2004 to July 27, 2005

NOTICE OF APPROVAL FOR PROTOCOL: IRB \#16308

TO: Lora Ford

C. Russell Jackson, Pamela Harrington, Mike Bagby, \& Charles Ponte

TITLE: The Effectiveness of Valdecoxib on Post-Endodontic Pain

AGENCY: N/A

The Institutional Review Board for the Protection of Human Research Subjects (IRB) has approved the project described above. Approval was based on the descriptive material and procedures you submitted for review. Should any changes in your protocol/consent form be necessary, prior approval must be obtained from the IRB.

According to the Code of Federal Regulations, Section 312.32, investigators are required to notify the FDA and the study sponsor of any adverse experience associated with the use of an investigational drug that is serious and unexpected. A serious adverse experience is considered any event that is fatal or life-threatening, is permanently disabling, requires inpatient hospitalization, or is a congenital anomaly, cancer, or overdose. An unexpected adverse experience is an event that is not identified in nature, severity, or frequency in the current investigator brochure. Any experience reportable to FDA and the sponsor must also be reported immediately to the IRB. If the study is funded, initiation of the protocol may not begin until the contract is finalized. 
Date: September 3, 2004

Page -2-

Ford

IRB \#16308

A consent form* $\mathrm{X}$ is__ is not required of each subject.

An assent form_ is $\mathrm{X}$ is not required of each subject.

A recruitment ad has has not $\mathrm{X}$ been approved.

A consent form waiver has_ has not $\mathrm{X}$ been approved.

An authorization form to use PHI has $\mathrm{X}$ has not been approved.

A PHI waiver has_ has not $\mathrm{X}$ been approved.

Only copies of the consent and/or assent form with the IRB's approval stamp may be used with human subject research. It is the responsibility of the investigator to submit a revised consent form for the IRB's approval should funding be obtained. This stamped consent form must then be used for subjects enrolled. A copy of each subject's signed Consent/Assent Form must be retained by the investigator and accessible to federal regulatory authorities for at least three years after the study is completed.

Lilo A. Ast
Senior Program Coordinator for
Research Compliance




\section{APPPENDIX B}

\section{PATIENT CONSENT FORM IRB PROTOCOL STATEMENT}




\section{WestVirginiaUniversity \\ SCHOOL OF DENTISTRY}

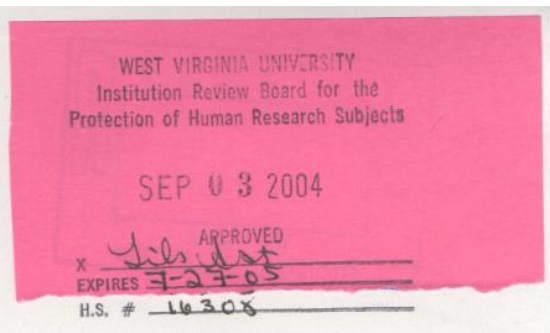

The Effectiveness of Valdecoxib on

Post-Endodontic Pain

\section{CONSENT AND INFORMATION FORM}

INTRODUCTION: I, , have been invited to participate in this research study in the Department of Endodontics, which has been explained to me by This research is being conducted by Lora Ford, DDS to fulfill the requirements of a master's thesis in Endodontics at West Virginia University.

PURPOSE OF STUDY: The purpose of this study is to learn more about the effectiveness of valdecoxib at controlling post-endodontic pain. Valdecoxib is a drug used to help control inflammation and pain that is associated with that inflammation. It is part of the drug class known as Non-Steroidal Anti-Inflammatory Drugs (NSAIDS). It causes less potential side effects like gastro-intestinal irritation, ulcers, and bleeding, that are sometimes experienced with the use of traditional NSAIDS such as ibuprofen. If the use of valdecoxib can significantly reduce the pain associated with inflammation with fewer side effects, perhaps it should be part of treatment protocol for root canal therapy.

DESCRIPTION OF PROCEDURES: This study involves a one time oral administration of either $20 \mathrm{mg}$ valdecoxib or $600 \mathrm{mg}$ ibuprofen immediately before root canal therapy. The drugs will be given to the participants of this study in a random fashion and according to a pre-determined schedule of administration. I understand that I will not be aware of which drug I am receiving. I will record my initial pain perception on the given questionnaire. Local anesthetic will be administered and standard root canal therapy will be initiated. If time permits, the root canal therapy will be completed, if not it will be scheduled for completion. Approximately 50 subjects will be entered in the study. I will be required to fill out a pain questionnaire immediately after treatment, 4 hours, 8 hours, 24 hours, 48 hours, and 72 hours after treatment. An extra dose of a different pain medication will be given and may be taken if the need arises. This additional pain medication is to be taken only if it is necessary to relieve the discomfort. I will record the degree of pain I am experiencing at the given time intervals on the questionnaire as well as if and when additional pain medication was needed. It will take approximately 30 seconds to record my level of discomfort at each time interval. Once I have completed the questionnaire I will return it via mail in the provided stamped envelope.

Version date $8-31-04$

Department of Endodontics

Robert C. Byrd Health Sciences Center PO Box 9450

Morgantown, WV 26506-9450
Page 1 of 3

Initials date




\title{
WestVirginiaUniversity \\ SCHOOL OF DENTISTRY
}

\author{
The Effectiveness of Valdecoxib on \\ Post-Endodontic Pain
}

RISKS AND DISCOMFORTS: There are no known or expected risks from participating in this study other than the normal possible side effects of non-steroidal anti-inflammatory drugs (NSAIDS). The risks of these side effects are categorized as more frequent, less frequent and rare:

More Frequent: skin rash, dizziness, gastrointestinal effects like cramps, pain/discomfort, epigastric pain or discomfort, heartburn, nausea.

Less Frequent: itching, ringing or buzzing in ears, fluid retention/edema, headache, nervousness or irritability, bloating or gas, constipation, decreased appetite, diarrhea, indigestion, vomiting.

Rare: unexplained nosebleeds, cardiac arrhythmias, exacerbation of congestive heart failure, increased blood pressure, confusion, hallucinations, aseptic meningitis, mental depression, peripheral neuropathy, hives or blisters, erythema multiforme, StevensJohnson syndrome, toxic epidermal necrolysis, gastritis, GI bleeding, GI ulcers, bleeding, blood in urine, cystitis, agranulocytosis, anemias, pancytopenia, eosinophilia, leukopenia, thrombocytopenia, jaundice, hypersensitivity reactions, angitis, angioedema,

bronchospastic allergic reactions, rhinitis, serum sickness like reaction, lupus-like syndrome, amblyopia, blurred vision, conjunctivitis, dry eyes, change in vision, gingival ulcers, change in hearing, pancreatitis, polyuria, renal impairment, renal necrosis, shortness of breath, fast heartbeat, hot flashes, pounding heartbeat, drowsiness, trouble sleeping, photosensitive dermatologic reactions, dry mouth.

Most of these side effects are seen with long term NSAID use and in this study only a one time dose will be given.

BENEFITS: I understand that this study is not expected to be of direct benefit to me, but the knowledge gained may be of benefit to others.

FINANCIAL CONSIDERATIONS: There are no special fees for participating in this study, but any expense associated with current therapy or treatment of side effects will be billed to me or my insurance company. The drugs for this study will be given free of charge; however the fee for the root canal therapy must be paid in full at time of completion. Once the data from this research has been collected, I will be compensated $\$ 15.00$ for my participation and returning the completed questionnaire.

Version date $8-31-04 \quad$ Page 2 of 3 


\title{
WestVirginiaUniversity \\ SCHOOL OF DENTISTRY
}

\author{
The Effectiveness of Valdecoxib on \\ Post-Endodontic Pain
}

ALTERNATIVES: Alternatives which could be considered in my case include root canal therapy without any medication for pain control or extraction of the offending tooth. Another alternative is not to participate.

VOLUNTARY COMPENSATION: If I am injured as a result of this research, treatment will be available. Compensation of my injuries will not be provided voluntarily by the investigator, West Virginia University, or other associated affiliates.

CONTACT PERSON: For more information, about this research, I can contact Dr. Lora Ford, at (304) 293-0627. For more information regarding my rights as a research subject, I may contact the Executive Secretary of the Institutional Review Board at (304) 293-7073.

CONFIDENTIALITY: I understand the information about me obtained as a result of my participation in this research will be kept as confidential as legally possible.

I understand also that my research records, just like hospital records, may be subpoenaed by court order or may be inspected by federal regulatory authorities. In any publications that may result from this research, neither my name nor any information from which I might be identified will be published without my consent.

VOLUNTARY COMPENSATION: Participation in this study is voluntary. I understand that I am free to withdraw my consent to participate in this study at any time. Refusal to participate or the decision to withdraw will involve no penalty or loss of benefits. I have been given the opportunity to review the questionnaire and ask questions about this research and I have received answers concerning areas I did not understand.

Upon signing this form, I will receive a copy.

I willingly consent to participate in this study.

Signature of Subject

Signature of Investigator

Version date 8-31-04 Page 3 of 3

\author{
Department of Endodontics \\ Robert C. Byrd Health Sciences Center \\ PO Box 9450 \\ Morgantown, WV 26506-9450
}

Date

Date 


\section{Authorization to Use or Disclose Protected Health Information (PHI)}

\section{West Virginia University}

I hereby voluntarily authorize the use or disclosure of my individually identifiable health information as described below.

Patient Name:

Date of Birth:
ID Number: IRB Protocol \#

16308

Persons/organizations providing the protected health information (e.g. hospitals): Patients from West Virginia University School of Dentistry Department of Endodontics

Persons/organizations receiving the information (e.g. investigators, clinical coordinators, sponsor, FDA):

Lora Ford D.D.S., Pamela Harrington D.D.S., C. Russell Jackson D.D.S., M.S., Mike Bagby, D.D.S., PhD, Charles D. Ponte, PharmD, C.D.E., B.C.P.S., B.C.-A.D.M., F.C.C.P., F.A.S.H.P., F.A.Ph.A.

The following information will be used:

Pain questionnaires will be evaluated and statistically analyzed. All PHI will be coded to protect the privacy of participating patients.

The information is being disclosed for the following purposes (Start with the Title of the study and include additional information e.g. screening and recruiting subjects; analyzing research data, or other specified purposes):

For the master's thesis project titled "The Effectiveness of Valdecoxib on Post-Endodontic Pain"

I may revoke this authorization at any time by notifying the Principal Investigator in writing at: Lora Ford DDS, 1088 Health Sciences North, P.O. Box 9450 Morgantown, WV 26506

If I do revoke my authorization, any information previously disclosed cannot be withdrawn. Once information about me is disclosed in accordance with this authorization, the recipient may redisclose it and the information may no longer be protected by federal privacy regulations. 


\section{Authorization to Use or Disclose Protected Health Information (Contd.)}

I may refuse to sign this authorization form. My clinical treatment may not be affected by whether or not I sign this form. I may not be allowed to participate in the research if I do not sign the form.

This authorization will expire on the date that the research study ends. (Other options for expiration include an actual date of expiration, occurrence of a particular event, or "none" if the authorization will have no expiration date.)

Expiration date: None

I will be given a copy of this authorization form.

Signature of subject or subject's legal representative

(Form MUST be completed before signing)

Printed name of subject's legal representative
Relationship to the subject
\begin{tabular}{|l}
\hline \\
Parent \\
Medical power of attorney/representative \\
Legal guardian \\
Health care surrogate
\end{tabular}

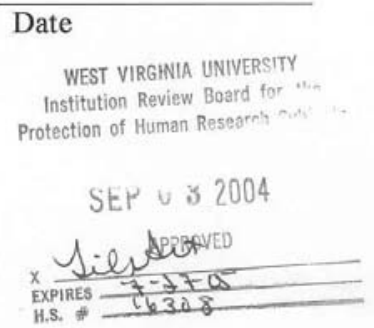

Page 2 of 2 
Form Revised May 2004

DO NOT WRITE IN THIS SPACE

\begin{tabular}{l|l}
\hline IRB \# & OSP\#
\end{tabular}

* Instructions on specific items can be obtained by clicking on the underlined links and from the last page of the form

\section{Institutional Review Board Protocol Statement*}

1. Title of study:** The Effectiveness of Valdecoxib on Post-Endodontic Pain.

** The protocol title should include the version and date for all addendums, investigator brochures, etc.

2. Review category requested: $\quad \mathrm{X}$ Quorum $\square$ Expedited (specify categories [1-6], see Chapter II of guidelines):

3. Level of risk to subjects: $\quad \mathrm{X}$ Minimal $\square$ More than minimal

4. Reason for conducting research: $\square$ Professional $\square$ Dissertation $\square$ Thesis $\square$ Class Assignment Faculty Advisor (name, PO box, phone, e-mail):

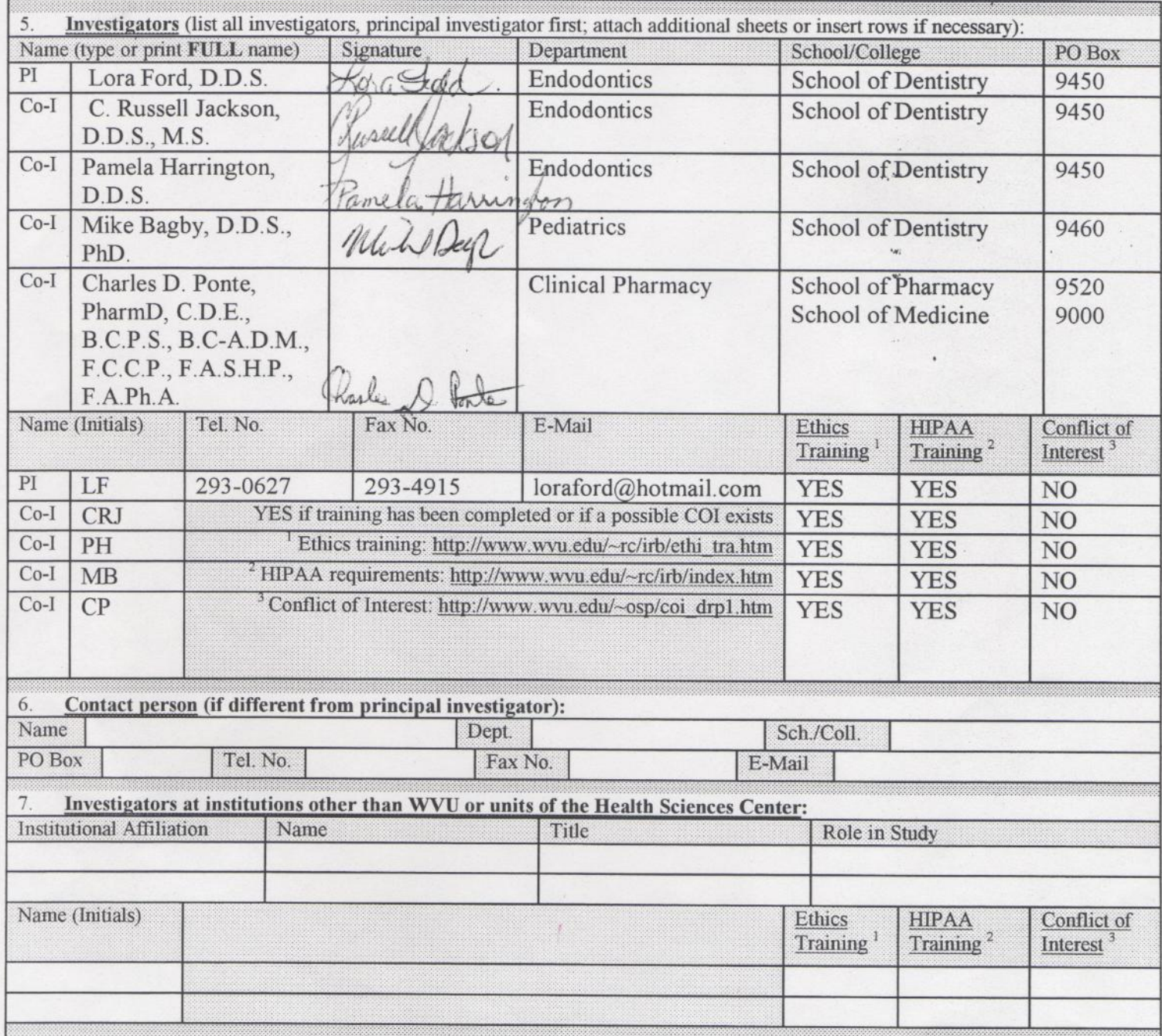




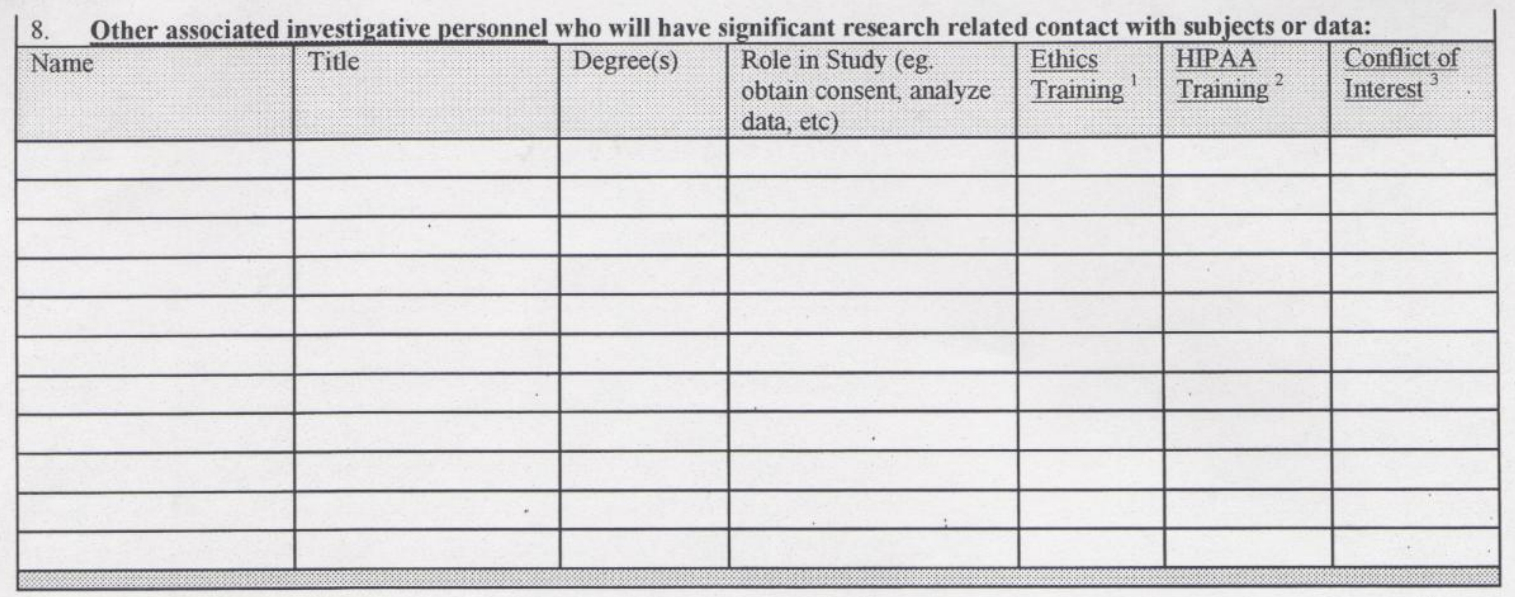




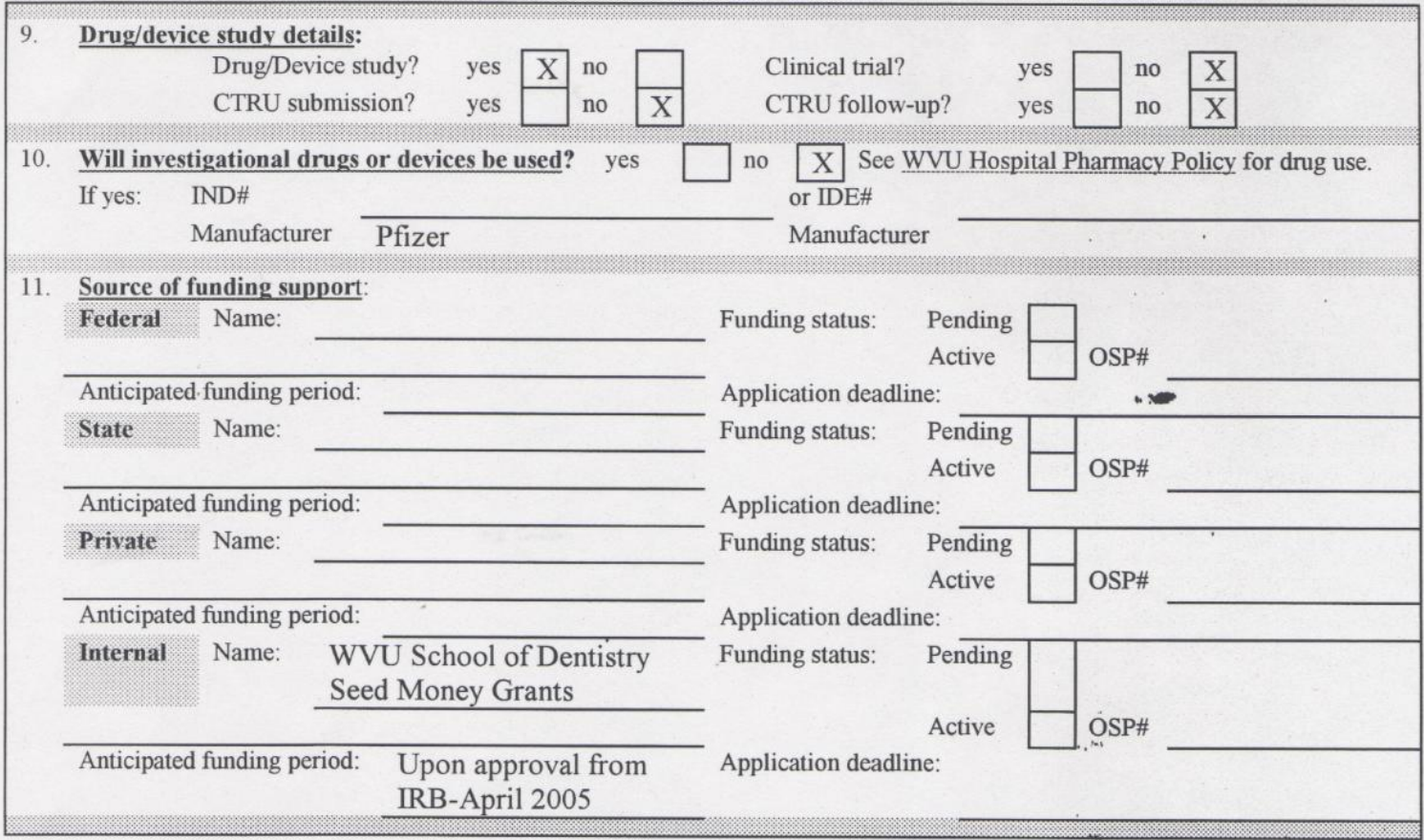

12. Human subject details: Total number of subjects to be enrolled nationwide 50 Enrolled by WVU researchers 50 Setting for interaction with subjects (provide name of institution, address, and brief description):

WVU School of Dentistry, Endodontic Clinic

\begin{tabular}{ll} 
Estimated period of human subject involvement: & Starting date: $\begin{array}{l}\text { Upon } \\
\text { approval from } \\
\text { the IRB }\end{array}$ \\
\cline { 1 - 1 }
\end{tabular}

13. Indicate with an $\mathbf{X}$ which of the following special populations will be targeted in the research Patients

Children (under 18)

Intellectually or emotionally impaired subjects

Pregnant subjects or fetuses

Prisoners, parolees, incarcerated subjects

Illiterate subjects

Subjects whose primary language is not English

Students or trainees

Employees of institutions associated with the study

Employees or subordinates of investigators
14. Indicate with an $\mathbf{X}$ if any of the following items are involved: (*** including electronic formats)

Analysis of records or tissues

Filming, videotaping, or voice-recording of subjects***

Questionnaires***

Ionizing radiation, either diagnostic or therapeutic

Pathological or diagnostic tissue or fluids

Placental tissue

Fetal tissue

Approved drug or device in "non-FDA-approved" application

Placebo(s)

Deception of subjects

Tissue banking

Genetic testing

Access to protected health information (PHI)

Radiation Safety Approval Date 
15. Will there be any financial remuneration, reward, reimbursement of expenses or other inducements to participate? \begin{tabular}{l|l|l|l|l} 
yes & $x$ & no & & (If yes, explain in item 3 of Discussion.)
\end{tabular}

16. Will there be any potential added cost to subjects?
yes
no
(If yes, explain in item 4 of Discussion.)

17. Method of obtaining informed consent: (Check all that apply) written consent form (include a copy in Section C)

waiver or alteration of consent process (explain in Section C) control group consent

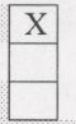

how many versions? 1 .

how many versions?

HIPAA requirements: (Check all that apply) individual authorization waiver of individual authorization

18. Method of obtaining assent from children (age 7-18) or subjects unable to sign legally valid consent: written assent form (include a copy in Section C) no assent, under age 7 or severely impaired (explain in Section C) waiver or alteration of assent process (explain in Section C) control group assent

how many versions?

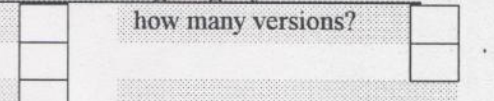

how many versions?

19. Will you use a cover letter? \begin{tabular}{l|l|l|l}
\hline yes & & no & $\mathrm{X}$
\end{tabular} (If yes, attach a copy.) Number of cover letter versions used: (Attach copies)

20. Will you use a recruitment ad? yes $\square$ no $\quad \mathrm{X}$ (If yes, attach a copy.) Number of recruitment ad versions used: (Attach copies)

21. Signatures: (The Board will not review the protocol without these signatures. By signing, department chairs acknowledge approval of this study on the basis of scientific merit and compliance with applicable professional standards; deans and other administrators signify their approval of the use of resources and faculty and student effort on the study. Multi-unit protocols require the signatures of each chair and dean.)

\begin{tabular}{|c|c|c|c|c|}
\hline-1 & Name (type or print) & Title & Signature, & Date \\
\hline Dean & Dr. Richard Crout & Associate Dean of Research & & $7-6-04$ \\
\hline \multicolumn{5}{|l|}{ Dean } \\
\hline Dept. Chair & Dr. C.Russell Jackson & $\begin{array}{l}\text { Professor and Chair, } \\
\text { Department of Endodontics }\end{array}$ & & \\
\hline Dept. Chair & & & 1 & 17 \\
\hline \multicolumn{5}{|l|}{ Hospital Admin. } \\
\hline \multicolumn{5}{|l|}{ Faculty Advisor } \\
\hline Other & & & & \\
\hline
\end{tabular}




\section{APPENDIX C}

\section{PAIN SURVEY}


Patient \#

SS\#
Tooth \#

DX

Date

$\ldots$ Time started

$\begin{array}{lc}\begin{array}{l}\text { Initial } \\ \text { Evaluation }\end{array} & \begin{array}{c}\text { Pain so } \\ \text { severe you } \\ \text { can't stand it }\end{array} \\ \begin{array}{ll}\text { Immediately None } & \text { Pain so } \\ \text { After RCT } & \text { severe you } \\ \text { can't stand it }\end{array}\end{array}$

4 hrs after None

Pain so severe you can't stand it

Was additional pain medication required? Yes No What time? GI distress?

8 hrs after None Pain so severe you can't stand it

Was additional pain medication required? Yes No What time? GI distress?

12 hrs after None Pain so severe you can't stand it

Was additional pain medication required? Yes No What time? GI distress?

24 hrs after None Pain so severe you can't stand it

Was additional pain medication required? Yes No What time? GI distress?

48 hrs after None Pain so severe you can't stand it

Was additional pain medication required? Yes No What time? GI distress?

72 hrs after None Pain so severe you can't stand it

Was additional pain medication required? Yes No What time? GI distress? 


\section{APPENDIX D}

\section{PULPAL AND PERIAPICAL DIAGNOSIS FLOW CHARTS}




\section{Pulpal Diagnosis}

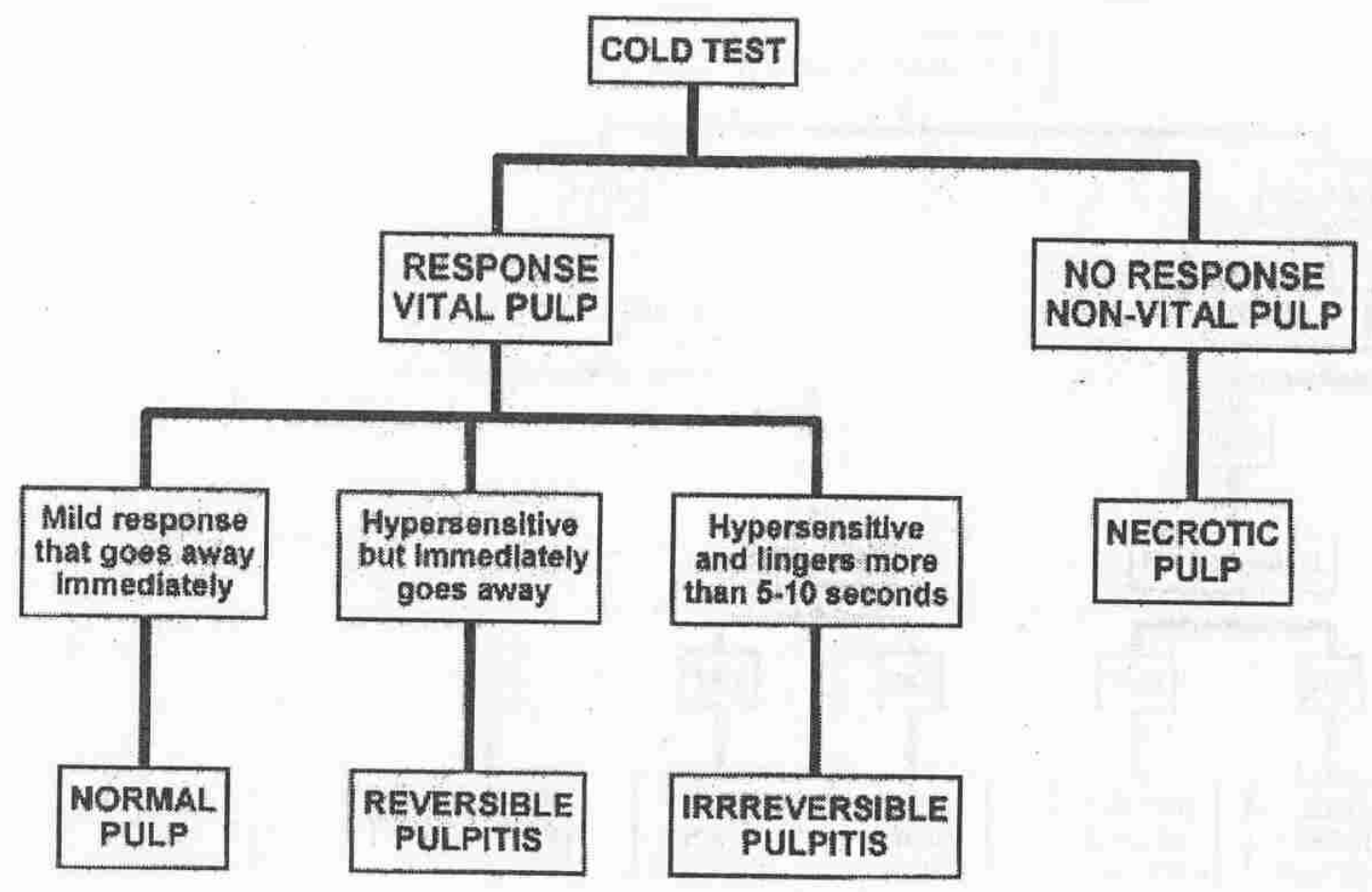




\section{Periapical Diagnosis}

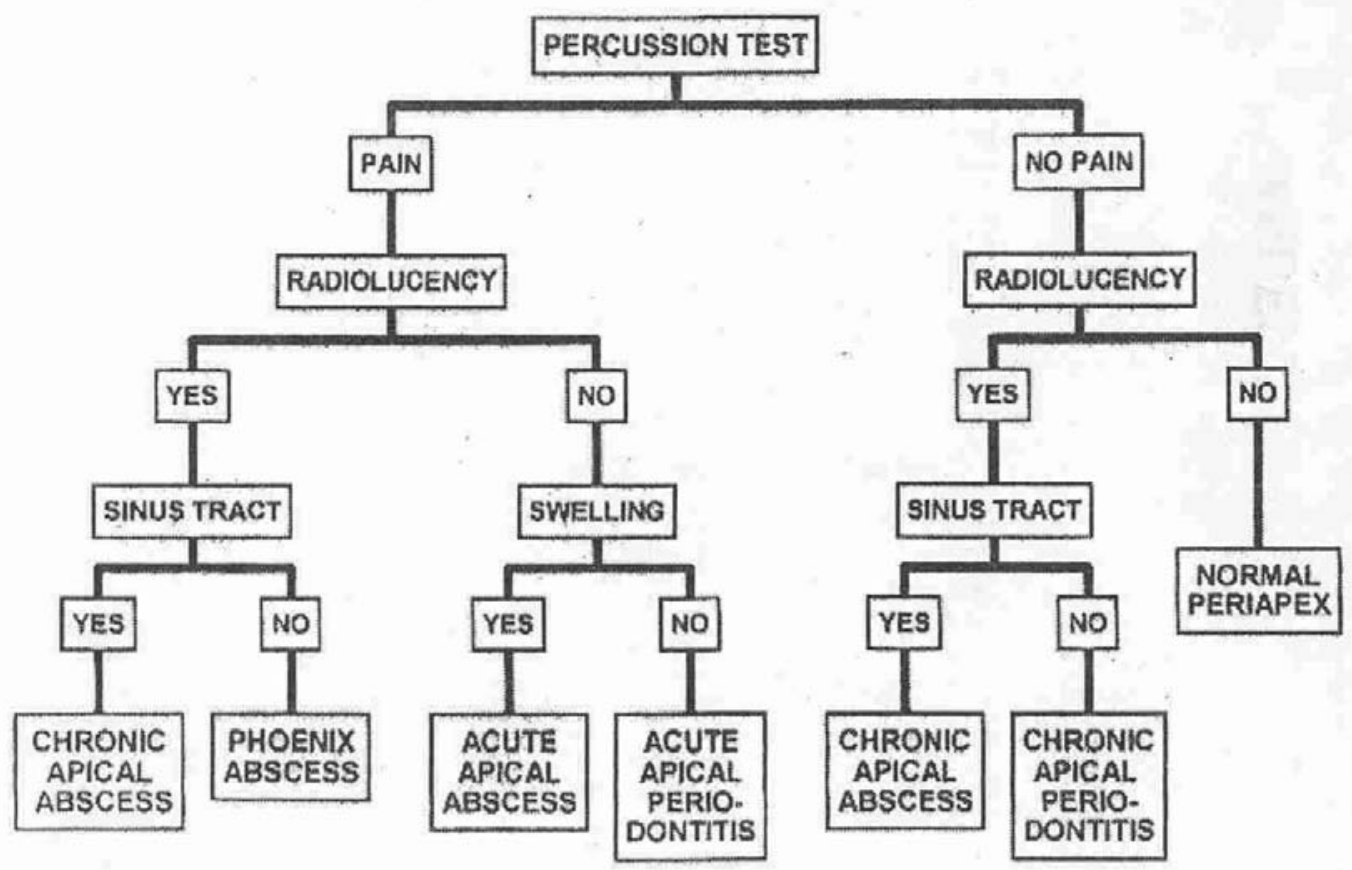




\section{APPENDIX E \\ MEDICATION SCHEDULE}


Randomization of Medication Dispersion

$\begin{array}{cc}\text { Subject } & \text { Med } \\ 1 & \mathrm{~b} \\ 2 & \mathrm{a} \\ 3 & \mathrm{a} \\ 4 & \mathrm{~b} \\ 5 & \mathrm{a} \\ 6 & \mathrm{~b} \\ 7 & \mathrm{~b} \\ 8 & \mathrm{~b} \\ 9 & \mathrm{~b} \\ 10 & \mathrm{~b} \\ 11 & \mathrm{~b} \\ 12 & \mathrm{~b} \\ 13 & \mathrm{a} \\ 14 & \mathrm{~b} \\ 15 & \mathrm{a} \\ 16 & \mathrm{a} \\ 17 & \mathrm{a} \\ 18 & \mathrm{a} \\ 19 & \mathrm{~b}\end{array}$




\section{CURRICULUM VITAE}

\section{Lora Beth Ford DDS, MS}

June 5, 1976

Honolulu, Hawaii

\section{EDUCATION}

West Virginia University M.S.

2003-2005

Certificate in

Endodontics

West Virginia University D.D.S.

1999-2003

West Virginia University B.S.D.H.

1995-1999

\section{PROFESSIONAL ORGANIZATIONS}

American Association of Endodontists

American Dental Association

Psi Omega Dental Fraternity

Secretary

Student American Dental Hygienists

Association

President

Secretary 2003-present

1999-present

2000-2003

2000-2001

1995-1999

1998-1999

1997-1998

\section{AWARDS}

Omicron Kappa Upsilon National Dental

2003

Honor Society

American Academy of Oral and

Maxillofacial Surgery Pathology

Award

WVU Local Anesthesia Award

2001-2003

Thomas P. Hinman Dental Society Scholarship

Kanawha Valley Dental Society Scholarship

Pierre Fauchard Academy Scholarship

WVU Alumni Association Award for Outstanding Clinical Competency and Professionalism

Sigma Phi Alpha National Dental Hygiene Honor Society
2002

2002

1999

2003

2002

1999 